\title{
Effect of thermal history on the properties of bentonite
}

\section{A. R. Estabragh}

Associate Professor. Faculty of Soil and Water Engineering, University of Tehran, PO BOX 4411 Karaj 31587-77871, Iran

Tel: +982632241119

Fax: +982632226181

Email: raeesi@ut.ac.ir

F. Khosravi

Postgraduate Student, Faculty of Soil and Water Engineering, University of Tehran, PO BOX 4411 Karaj 31587-77871, Iran

Tel: +982632241119

Fax: +982632226181

Email: fkhosravi68@ut.ac.ir

\section{A. A. Javadi}

Professor. Computational Geomechanics Group, Department of Engineering, University of Exeter, Devon, EX4 4QF, UK

Tel: +441392723640

Fax: +441392217965

Email: $\underline{\text { A.A.Javadi@exeter.ac.uk }}$ 


\title{
Effect of thermal history on the properties of bentonite
}

\begin{abstract}
The effect of thermal history on the properties of bentonite was studied through a number of experimental tests. The desired thermal history was created on samples of bentonite by keeping them at a fixed temperature $\left(50,100,150,200\right.$ and $\left.250^{\circ} \mathrm{C}\right)$ for a specific duration $(3,7,14$ and 30 days). Standard compaction, Atterberg limits, free swelling and swelling pressure tests were carried out on the samples on the dry side of optimum, optimum and wet side of optimum of the compaction curve with desired thermal history. In addition chemical tests were carried out on the flooding water at the end of the swelling test. The results showed that the changes in compaction characteristics were not considerable but the Atterberg limits, free swelling and swelling pressure of the soil were changed due to the thermal history in comparison with the soil without any thermal history. The magnitudes of free swelling and swelling pressure were dependent on the location of prepared sample on the compaction curve. In addition, the changes in Atteberg limits and swelling parameters (amount of free swelling and swelling pressure) were functions of magnitude of temperature and duration of time that the sample experienced the temperature in its temperature history. The effects of temperature and also duration of exposure of the soil to temperature was discussed with the aid of the Diffuse Double Layer (DDL) theory. It was found that the temperature may change the gradation of soil due to cementation of particles as a result of formation of some salts and oxides that help to paste the particles together and change the properties of the soil.

Key word: Thermal history, bentonite, Atterberg limits, compaction, swelling test
\end{abstract}




\section{Introduction}

Determination of the effect of temperature on the properties of soils is an important problem in Geoenvironmental Engineering. Soils may be subjected to various conditions of high or low temperature. Thermal effects are generally induced in two cases: high temperature resulting from a heat source in ground and low temperature in response to seasonal temperature change of frozen ground. Over the last 50 years researchers have investigated the effect of temperature on the behaviour of soils. For the first time Youssef et al. (1961) studied the effect of temperature on the physical parameters such as Atterberg limits and compaction characteristics of a soil. They indicated that increasing the temperature will cause a reduction of liquid limit and plastic limit. Laguros (1969) conducted a number of similar tests on kaolinite, illite and monmorillonite and found that increasing in temperature leads to reduction in liquid limit and plastic limit. The effect of heating on the plasticity characteristics of soils also depends on clay mineral type (Wang et al., 1990). In general, the plastic limit does not change the same as the liquid limit and plasticity index. The soils that include kaolinite have less tolerance to temperature than soils containing montmorillonite as the predominant clay minerals. Therefore, when a cohesive soil is heated to a certain temperature it may change the plasticity of the soil and its clay minerals. Wang et al. (1990) concluded from experimental tests on kaolinite (in the range of temperatures from 20 to $400^{\circ} \mathrm{C}$ ) that temperature does not have any significant effect on the Atterberg limits. Similar results were also reported by Towhata et al. (1993).

The effect of temperature on the volume change behaviour of saturated soils has been investigated by a number of researchers such as Plum and Esrig (1969), Houston et al. 
(1985), Hueckel and Baldi (1990), Boudali et al. (1994), Delage et al. (2000), Graham

et al. (2001), Villar and Lloret (2004), Romero et al.(2005) and Tang et al. (2008). The effect of temperature on swelling of unsaturated soil was studied by Volckaert and Manfroy (1992), Volckaert et al. (1993) and Towhata et al. (1993) who showed that the magnitude of swelling of a soil is dependent on the applied temperature. Lambe (1962) showed that the swelling index of a clay soil changed to about one half at $500^{\circ} \mathrm{C}$ and to about one quarter at $750^{\circ} \mathrm{C}$. Gupta and Dutta (1967) reported that black cotton soil that has montmorillnite as the predominant clay mineral, can be changed into a water-resistant material when is heated to a temperature less than $360^{\circ} \mathrm{C}$. On the other hand Beles and Stanculescu (1958) indicated that the amount of swelling of a loess soil can be changed considerably at temperatures over $800^{\circ} \mathrm{C}$. Volckaert and Manfroy (1992) reported that the variation of temperature can cause change in the initial suction of the sample. They showed that by reducing the temperature of a clay soil sample to $22^{0} \mathrm{C}$ the initial suction of the soil $(5000 \mathrm{kPa})$ was reduced to $10 \mathrm{kPa}$ and this was followed by $11.3 \%$ increase in the volume of the soil. They changed the temperature to $77^{\circ} \mathrm{C}$ on another sample of the same soil and observed $8.8 \%$ reduction in the volume of the sample. This shows that the variation the volume of sample is dependent on changes of temperature. Pusch et al. (1990) and Cho et al. (2000) showed that increase in temperature induced increase in the swelling pressure of bentonite. Romero et al. (2003) studied the effects of temperature in controlled-suction swelling pressure test for compacted Boom clay. They concluded that the values of swelling pressure at each equilibrium suction (i.e., 4500, 2000, 600 $\mathrm{kPa}$ and saturated condition) at $22^{\circ} \mathrm{C}$ are more than those at $80^{\circ} \mathrm{C}$.

\section{Aim of this study}


Bentonite is an expansive soil that has a high plasticity, low permeability and high swelling potential. These properties make it suitable to use as a buffer and sealing material for liner and cover of landfills. Due to low permeability of compacted bentonite the transportation of contaminants from disposal waste or from landfill to groundwater is minimized. The temperature of disposal waste may change with time and the variations of it can change the behaviour of bentonite. It can be said that, the same way that a soil can have a stress history, it can also have a thermal history. The review of literature shows that although a lot of research has been carried out on the effect of temperature on properties of clay soil, but the effect of temperature history on the behaviour of soils has not been considered. The aim of this work is to investigate the effect of thermal history on the physical and mechanical properties of an expansive soil including Atterberg limits, compaction characteristics, swelling potential and swelling pressure. A series of experimental tests were performed on samples of bentonite that were subjected to different temperature histories. The effects of temperature at a given time and also the effects of time at a constant temperature were investigated.

\section{Material and experimental procedure}

The basic material for this study was bentonite of type Na-Montmorillonite that was acquired commercially. The physical and mechanical tests were conducted on samples of bentonite at $25^{\circ} \mathrm{C}$ in a temperature controlled laboratory. The results showed the specific gravity of the soil was 2.75 . It had liquid limit (LL), Plastic limit (PL) and Plastic index (PI) equal to $349.70 \%, 55.10 \%$ and $294.60 \%$ respectively (see

Fig.1). Compaction test was carried out on the soil according to the ASTM D698-12. The optimum water content and maximum dry unit weight were $37.70 \%$ and 11.60 $\mathrm{kN} / \mathrm{m}^{3}$ respectively. According to the Unified Soil Classification System (USCS), this 
soil can be classified as $\mathrm{CH}$ (clay with high plasticity). The results of chemical tests showed that the percent content of organic matter (O.C.) and CEC (Cation Excahnge Capacity) of the soil were $0.072 \%$ and $74.1 \mathrm{meq} / 100 \mathrm{~g}$ respectively with $\mathrm{Na}^{+}$as the main cation. According to the information that was obtained from the seller of bentonite the chemical contents of it were $62.9 \% \mathrm{SiO}_{2}, 19.6 \% \mathrm{Al}_{2} \mathrm{O}_{3}, 3.35 \%$ $\mathrm{Fe}_{2} \mathrm{O}_{3}, 3.05 \% \mathrm{MgO}, 1.68 \% \mathrm{CaO}, 1.53 \% \mathrm{Na}_{2} \mathrm{O}, 0.53 \% \mathrm{~K}_{2} \mathrm{O}, 0.32 \% \mathrm{FeO}, 0.111 \% \mathrm{~F}$, $0.09 \% \mathrm{TiO} 2,0.05 \% \mathrm{~S}, 0.049 \% \mathrm{P} 2 \mathrm{O} 3,0.006 \%$ traces. The $\mathrm{pH}$ and $\mathrm{EC}$ (electrical Conductivity) of the soil were 8.25 and $4.92 \mathrm{dS} / \mathrm{m}$. Distilled water with $\mathrm{pH}$ and EC (electrical Conductivity) equal to 7.0 and $10 \mu \mathrm{s} / \mathrm{cm}$ was used for preparing the samples and flooding the samples during the swelling tests.

The temperatures and the times that were chosen for creating the desired thermal history were $50^{\circ}, 100^{\circ}, 150^{\circ}, 200^{\circ}$ and $250^{\circ} \mathrm{C}$ and $3,7,14$ and 30 days. A number of soil samples (about $5 \mathrm{~kg}$ ) were kept in oven at one of the above temperatures and periods of time to experience the desired thermal history. After this period the samples were kept out in the laboratory temperature of about $25^{\circ} \mathrm{C}$ for about one week. The standard compaction and Atterberg limit tests were carried out on these soil samples according to ASTM standards. For the swelling tests, in order to obtain uniform and repeatable samples a mould was designed and made from stainless steel. The mould was a split compaction mould which consisted of three sections: a top collar, a middle section and a bottom collar. The dimensions of the middle section were exactly the same as those of the ring of the oedometer. The mould was provided with a piston that was used to compress the sample inside the mould. Silicon grease was used, before compacting, to the inner surface of the mould to reduce the friction during compaction. The samples were prepared by static compaction of the moist soil in the mould in three layers to a given dry unit weight and water content (5\% less than 
optimum, 5\% more than optimum and optimum water content). To prepare the samples three desired weights of soil were mixed with water at optimum moisture content, $5 \%$ less or $5 \%$ more than optimum water content corresponding to the compaction curve. The mixtures were kept in closed plastic bags for nearly 6 days. This allowed the distribution of moisture throughout the mass of the soil. The compaction pressure applied to each layer was not the same for different cases (soils of different thermal histories) and also for the samples on the dry, wet and optimum water contents. The compaction pressure was determined by trial and error by repeating compaction for different conditions of soil to achieve the dry unit weight corresponding to the desired water content on compaction curve. After determining the required pressure for each layer the sample was compacted to the desired vertical pressure in a compression loading frame at the displacement rate of $1.5 \mathrm{~mm} / \mathrm{min}$. Before placing the next layer the surface of compacted layer was scarified so that there was a good bond between adjacent layers of soil. The free swelling tests were carried out according to ASTM D 4546-08 on samples of the expansive soil in a conventional oedometer. The test sample was prepared with saturated porous stones at the top and bottom and then was placed in the consolidation apparatus. A seating pressure of $6.12 \mathrm{kpa}$ was applied. The sample was inundated with distilled water and allowed to swell. In the tests the axial deformation of sample was recorded with time. The tests were continued until the axial deformation reached to a constant value. The percent of swelling $(S \%)$ is defined as $\left(\Delta h / h_{i}\right) * 100$, where $h_{i}$ is the initial thickness of sample and $\Delta h$ is the increase in thickness at a given time. The swell potential is defined as the maximum percent of swell that the sample can achieve. The swell pressure is defined as the total vertical pressure needed by a sample to achieve zero axial strain (ASTM D4546-08). The swelling pressure for the samples was determined 
based on the swell under load method as used by Sridharan et al. (1986) and Rao and Thyagaraj (2007). In this method the sample is inundated with distilled water. Then, in a number of increments, the incurred swelling is eliminated by applying pressure on the sample. The variations of the incurred axial deformations are plotted against the applied pressures. The total vertical pressure at which the axial deformation of sample is zero is defined as the swelling pressure of the sample. At the end of each swelling test a number samples were taken of the flooding water and chemical tests were conducted to measure the $\mathrm{pH}, \mathrm{EC}, \mathrm{Na}^{+}$and $\mathrm{Ca}^{++}$on the samples. The swell pressure is defined as the total vertical pressure needed by a sample to achieve zero axial strain (ASTM D4546-08). The swelling pressure for the samples was determined based on the swell under load method as used by Sridharan et al. (1986) and Rao and Thyagaraj (2007). In this method the sample is inundated with water. Then, in a number of increments, the incurred swelling is eliminated by applying pressure on the sample. The variations of the incurred axial deformations are plotted against the applied pressures. The total vertical pressure at which the axial deformation of sample is zero is defined as the swelling pressure of the sample.

\section{Results}

Figs.1 a and b show the variations of liquid limit (LL) and plasticity index (PI) of the soil with temperature for different times. The variations of LL for the time of 3 days are not very significant for various applied temperatures. For 7, 14 and 30 days and particularly beyond $50^{\circ} \mathrm{C}$ the changes in the value of LL become considerable. The value of LL for natural soil is $349.70 \%$ but at temperature of 250 for 30 days it was changed to $155 \%$ which shows a reduction of about $50 \%$. Therefore, LL decreases by increasing the time and temperature. A similar trend is seen in Fig. $1 \mathrm{~b}$ for variations of PI. 
The results of the compaction tests including maximum dry unit weight and optimum water content for the samples with different thermal histories are shown in Fig.2 . As shown in Fig.2a , the variation of maximum dry unit weight is not considerable but the optimum water content (Fig.2b) shows significant changes. The value of optimum water content at temperature of $50^{\circ} \mathrm{C}$ for heating time of 3 days is $37 \%$ and for temperature of $200^{\circ} \mathrm{C}$ and the same duration ( 3 days) it changes to $33.40 \%$. This figure (Fig.2b) shows that at a constant temperature the optimum water content is decreased with time. For temperature of $200^{\circ} \mathrm{C}$ the optimum water content is reduced from $33.40 \%$ for heating time of 3 days to $28.50 \%$ with heating time of 30 days.

The free swelling and swelling pressure tests for various samples involved 108 tests (54 free swelling and 54 swelling pressure tests). The results of free swelling and swelling pressure tests for the natural soil at optimum water content and water contents on the dry and wet sides of optimum are shown in Fig.3. As shown in Fig.3a the time of equilibrium is 480 hours and the magnitude of swelling for the samples on the dry side, optimum and wet side are $136,131.50$ and $115.50 \%$ respectively. This shows that the potential of swelling on the dry side is more than the optimum and particularly the wet side. Fig.3b shows the values of swelling pressures for the samples on the wet, optimum and dry sides; the values of swelling pressure for these samples are 890,820 and $750 \mathrm{kPa}$ respectively. It is resulted that higher free swelling causes higher swelling pressure. Fig 4 shows the results of free swelling and swelling pressure tests for the soil with thermal history of $100^{\circ} \mathrm{C}$ with the time of 3 days. As shown in Fig.4a the equilibrium is attained after nearly 456 hours and the values of free swelling are $108.25,99.50$ and $93.76 \%$ for the samples prepared on the dry, optimum and wet sides of the compaction curve. In this case reduction is observed in the samples tested on the optimum and wet side of optimum moisture contents 
relative to the sample tested on the dry side. In Fig. $4 \mathrm{~b}$ the variations of swelling pressure is seen for three types of sample. The swelling pressures are 700, 650 and $575 \mathrm{kPa}$ for samples on the dry, optimum and wet sides. The variations of free swelling with time for samples with thermal history of $\mathrm{T}=100^{\circ} \mathrm{C}$ and time of 30 days are shown in Fig.5a. As shown in this figure, the potential of swelling for wet samples is $96.25 \%$ that is less than the dry $(114.85 \%)$ and optimum samples $(105.40 \%)$. In Fig.5b the swelling pressures are shown for these samples. The value of swelling pressure for the wet sample is $550 \mathrm{kPa}$ and those for the optimum and dry samples are 650 and $697 \mathrm{kPa}$; so the swelling pressure for dry sample is more than optimum and wet samples. The final swelling values of the samples for different conditions (dry, optimum and wet) at different temperatures and times, calculated from the corresponding results of percent swelling with time (a typical curve is shown in Fig.3), are shown in Figs.6a, b and c. As shown in these figures, for a specific time, the final swelling is reduced with increasing temperature and at constant temperature it is reduced with increasing the time. Figs. $7 \mathrm{a}, \mathrm{b}$ and $\mathrm{c}$ show the swelling pressure for samples at different conditions for different times and temperatures. The trend of variations of it is similar to the final swelling.

A total of 54 chemical tests were conducted on the samples taken from the flooding water. The chemical tests consisted of measuring $\mathrm{pH}, \mathrm{EC}$ and $\mathrm{Na}^{+}$. Figs.8a, b and c show the variations of $\mathrm{pH}, \mathrm{EC}$ (Electrical conductivity) and $\mathrm{Na}^{+}$in the flooding water at the equilibrium condition of swelling for duration of 14 days for different applied temperatures. As shown in these figures the order of curves for the dry, optimum and wet conditions is similar to the free swelling or swelling pressure curves for dry, optimum and wet side samples. These figures show that by increasing the temperature the $\mathrm{pH}$ was reduced; for the samples prepared on the dry side the value of $\mathrm{pH}$ at $50^{\circ} \mathrm{C}$ 
is 8.44 and at $250^{\circ} \mathrm{C}$ it is 6.88 showing a reduction of $18.48 \%$. This trend is shown in Fig.8b for variation of EC; so, by increasing the temperature a reduction in the values of EC is observed. Fig.8c shows the variation of $\mathrm{Na}^{+}$in the flooding water for different samples at equilibrium condition, indicating reduction in the amount of $\mathrm{Na}^{+}$ with increasing temperature.

\section{Discussion}

Bentonite is a highly plastic clay which contains quantity of montmorillonite (or smectites) and expands when it is in contact with water. This is related to the mineralogical composition of the structural unit of montmorillonite. The structure of montmorillonite is a unit made of an alumina octahedron sheet sandwhiched between two silica tetrahedron sheets (Mitchell 1993). The alumina octahedrn structure is composed of an aluminium atom and form particle coordination. In general clay surfaces in dry or wet condition carry an unbalanced negative charge, that attracts positive ions (cations). These positive ions become tightly attracted to a dry surface of clay. In addition to cations needed for the electrical neutrality of the clay surface. There are generally some salt precipitation comprising a combination of cations and anions. On addition of water these ions go into the solution. Desorption of cations from the clay surface leads to higher concentration of cations near the clay surface than concentration of cations farther away which makes the cations have a tendency to diffuse farther away. This diffusing tendency is however opposed by the attractive force between the cations and negative particle surfaces. The net result of these opposing trends is an ion distribution in the vicinity of the clay particles. This system of distributed charge surface is termed diffuse double layer (DDL). However, the DDL is formed on the external surface of clay particles and the volume of attracted water and thickness of DDL are dependent on the area of this surface. The DDL can 
be developed for an individual unit layer as well as clay platelets. The DDLs of the neighbouring unit layers or clay platelets interact, resulting in a net repulsive force between the unit layers or platelets. Attractive molecular forces however develop between two double layers if they approach extremely close to each other. The motion of electrons around the nucleus of different atoms and molecules in the system give rise to fluctuating dipoles having opposite electrical charge at their ends. The oppositely charged ends of different fluctuating dipoles attract each other. London (1937) developed a theory for attractive force between two molecules. The attractive forces are commonly termed as the London van der Waals forces. The advantage of the DDL theory is that the effects of factors such as cation valence, dielectric constant, electrolyte concentration, and temperature on the thickness of double layer can be readily determined. Hence, the physical and chemical properties of the pore fluid have a significant effect on the behaviour of clay minerals. Several studies have shown that the volume change in clays due to water-cations interaction can be predicated based on Guy-Chapman theory (Mitchell, 1993). A number of important contributions have been made to better understand the influence of DDL on clay behaviour (Olson and Mesri, 1970; Mesri and Olson, 1971 and Sridharan and Rao, 1973). Moreover, intensive research has focuced on computing the swelling pressure by employing the Guy-Chapman DDL theory (Pusch et al. 1990; Komine and Ogata, 1996 and 2003 and Sridharan and Choudhury, 2002).

The results of the Atterberg limit tests showed that increasing the temperature caused a decrease in liquid limit and plasticity index (see Fig.1). This can be explained by the fact that increasing the temperature caused the particles of clay soil to paste to each other and form bigger particles. Blight (1988) and Fookes (1997) argue that generally all tropical residual soils are affected in some way by drying. The liberated aluminium 
and iron during heating are rapidly oxidised and precipitated around clay particles and cement clay particles together to form large aggregates (White, 2006). Fookes (1997) discussed that even partial drying at moderate temperatures might change the structure and physical behaviour of tropical residual soils. He indicated that although oven-drying from $105^{\circ}$ to $110^{\circ} \mathrm{C}$ frequently has a substantial effect on soil properties but drying at a lower temperature (e.g. $50^{\circ} \mathrm{C}$ ), and even partial air-drying at ambient laboratory temperature can also produce significant changes. This process results in decreasing the specific surface which in turn causes reduction in the capacity of particles to absorb water and reduction of the Atterberg limits. These findings are in agreement with the results that were reported by Zhang et al. (2004) who concluded (from conducting Atterberg limits tests on the air-drying and oven- drying samples) that Atterberg limits, particularly plastic limit and plastic index, are reduced. Zhang et al. (2004) indicated that the DDL probably has the most important role in controlling soil plasticity as it significantly affects the amount of water attracted to the surface of clay minerals. They stated that the external surface of particles, quality of pore water and the valence of exchangeable cation are important factors that influence on the soil plasticity. Hammel et al. (1983) presented a relationship between the external surface and Atterberg limits. It can be said that the type of the soil minerals, pore fluid salt concentration and cation valance affect the surface area of soil and thickness of DDL. According to the DDL theory an increase in temperature should cause an increase in the DDL thickness and a decrease in the surface potential for a constant surface charge. It was indicated by Mitchell (1993) that the thickness of the diffuse double layer increases as the dielectric constant increases, whereas for a constant surface charge, the surface potential increases as dielectric constant decreases. Therefore, an increase in temperature will result in decrease in diffuse double layer thickness and 
increase in surface potential of clay. According to Zhang et al. (2004) the process that occurs during soil drying can be divided into mechanical, physico-chemical and chemical. They stated that the physico-chemical process involves the loss of DDL layer, adsorbed and absorbed layer so it affects the Atterberg limits. Fookes (1997) pointed out that dehydrated Fe oxides create strong bonds between clay particles and prevent from penetrating of water. This process is not reversible by rewetting. It can cause a significant increase in particle size and reduction in plasticity of soil. Zhang et al. (2004) Shakhawat Hossain (2001) also used the Fookes' explanation to describe the reduction of soil plasticity during drying. During chemical process the soluble salts are precipitated from the pore water solution. If the pore water contains a high concentration of soluble salts the precipitation is usually formed at particle contacts and can act as cementation that bonds particle tighter. If some of the newly formed participates are insoluble in water. This process is irreversible that is the precipitation will tend to increase the particle size and decrease the plasticity. Fig. 6 shows the variation of free swelling against time for different temperatures for the samples on the dry, optimum and wet sides of the compaction curve. The results show that, at a constant temperature, the potential of swelling is reduced with increasing the time and at a constant time, increasing the temperature caused further reduction in swelling potential. Comparison the results in Figs.6a, $\mathrm{b}$ and $\mathrm{c}$ indicates that the variations of swelling are more for the samples on the dry side than the wet side. The results show that the potential of swelling for all samples (natural soil and soil with thermal history) prepared on dry side of compaction curve is more than those prepared on wet side. The total specific surface is very high for bentonite clay and it carries a large number of net negative charges. As a result high surface energy develops at dry condition (Yan and Luo, 1995). Upon water uptake the surface energy of such clay 
minerals can cause volume changes under free swelling condition and can generate swell induced pressure constrained boundary conditions. The swelling process in bentonite is a result of changes of the interlayer structure within the expansive bentonite minerals. The mechanism of swelling and this difference on the dry and wet conditions can be explained as follows:

The samples used, with the same dry unit weight but two different water contents (on dry and wet sides of the compaction curve), would have different suctions. The suction on the dry side of the compaction curve would be more than the wet side. Before flooding, the soil samples are in unsaturated state. They have two suction components: matric suction $(s)$ that arises from capillary phenomenon in unsaturated voids and osmotic suction $(\pi)$ from the presence of salts in soil water (Fredlund and Rahardjo, 1993). When the soil sample is placed in the apparatus, it is in unsaturated state. By flooding the sample with water, the flow of water from the reservoir to soil sample will be continued until the matric suction is vanished and the sample becomes saturated. When the samples are exposed to water, the absorbed water on wet side of optimum is less than dry side (because of lower suction). The thickness of doublelayer water film on the wet side is more than the dry side of compaction curve. The matric suction is dependent on the water content or degree of saturation of sample. The matric suction on the dry side of optimum (with the same initial dry unit weight) is more than the wet side because the thickness of double layer in wet side is more than dry side (Gens, 1996). Samples on both dry and wet sides have the same osmotic suction because of the same salt concentration. By flooding the sample with water the flow of water from the reservoir to soil sample will continue until the matric suction is dissipated and saturated condition is attained. Therefore, when the samples are exposed to water the flow of water on the dry side of optimum is more than the wet 
side because of the smaller thickness of double layer of water around the particle, higher suction and higher over consolidation ratio which leads to greater swelling in comparison to samples prepared on the wet side of compaction curve.

Fig.7 shows the variations of swelling pressure against time for different temperatures $\left(50,100,150\right.$ and $\left.200^{\circ} \mathrm{C}\right)$ at various times for dry, optimum and wet conditions. As shown in this figure, for each condition of sample both the temperature and duration of heating cause reduction in swelling pressure. The results show that both potential of swelling and swelling pressure are reduced with increasing the temperature and duration of heating for samples on dry and wet sides of compaction curve and optimum point.

There are two predominant physico-chemical interactions between clay particles and within the adsorbed water layer as van der Walls and attractive forces. Therefore, it can be said that the adsorbed layer acts as an electrolytic solution allowing electrostatic interactions which make ionic exchange occur between the negatively charged clay particle surfaces and the pore water. This process of ion exchange results in electrostatic repulsion between clay particles and is called double layer repulsion (Anandarajah 1995). Evans (1991) and Yong et al. (1992) stated that an increase in temperature may change the attractive and repulsive forces and this can change the charges on the clay particles. They also indicated that heat induces ion exchange inside the diffuse double layer and this action may change the thickness of the diffuse double layer. It is resulted that increasing the temperature can significantly change the nature of the adsorbed water and may result in reorientation of soil particles and finally change the initial fabric of the soil. Yong et al. (1992) and Evans (1991) stated that the increase in temperature increases the rate of adsorption of ions from the pore water to the particle surface. In addition to the above discussion it can be said that 
heating may change the soil mineral to a new one with a lower capacity of adsorbed water than the initial condition. de La Fuente et al. (2000) found that the transformation to illite occurred when a bentonite underwent heating at temperature of $120-160^{\circ} \mathrm{C}$ for $180-360$ days. Drief et al. (2002) found that the transformation from smectite to illite also occurred when the sample was heated up to $50^{\circ} \mathrm{C}$ for 30 days in enriched sea water. Wersin et al. (2006) indicated that the increase in temperature may cause the smectite mineral to become unstable and transform to more stable silicate plates in a process which is known as illiation.

The results of chemical tests (Fig.8) showed that by increasing the temperature and duration of heating the concentration of ions, particularly $\mathrm{Na}^{+}$, is decreased in the flooding water of samples. This reduction indicates that some of ions are adsorbed to particles and changes occur to orientation of particles. Particles link with each other and create a new fabric of soil with lower specific surface that leads to reduction of swelling potential as shown by Almanaza et al, (1995). These findings are not in agreement with the results that were reported by Komine (2013) who indicated that the concentration of some exchange ions such as $\mathrm{Na}^{+}$is decreased with increasing the temperature. This may be due to different minerals of the soils used and different methods of testing because he carried out the heating tests on samples under surcharge pressure of 500 or $1000 \mathrm{kPa}$ with different initial densities.

As described in the introduction, the swelling behaviour of bentonite has a very important role in protecting the environment from pollution when it is used as a cover and liner. When bentonite is used as a buffer and sealing material for liner and cover in landfills the design should consider its behaviour with changes of temperature that may be produced from the disposed contaminated material.

\section{Conclusion}


In this study the variations of mechanical and physical parameters of bentonite due to the effect of thermal history was investigated through a set of experimental tests. The following conclusions can be drawn from this work:

1- The effect of thermal history on the dry unit weight is not considerable but it causes a reduction in optimum water content that is a function of temperature and duration of heating.

2- Atterberg limits (liquid limit and plasticity index) are decreased with increasing the temperature and duration of heating.

3- Swelling potential and swelling pressure for samples on dry, optimum and wet sides of compaction curve are not the same. For samples on the dry side of optimum, the swelling potential is more than the other two cases. Swelling potential and swelling pressure are functions of temperature and duration of experienced temperature. Increasing the temperature and duration of heating is effective in reducing the swelling behaviour.

4- Ion concentration of flooding water of samples is reduced by increasing the temperature and duration of heating. 


\section{References}

Almanza R, Castaneda R, Silva G (1995) Temperature-electrolyte effects on clay soil liners. Proceeding of First International Conference on Unsatyurated Soils. Paris, France, pp. 343-346.

Alonso EE, Romero E, Hoffmann C, Carcỉa-Escudero E (2005) Expansive bentonitesand mixtures in cyclic controlled-suction drying and wetting. Eng Geol 8: 213-226.

Anandarajah A (1995) Physical-chemical interaction between clay particles in a fluid. International Workshop on Hydro-thermo-Mechanics of Engineered Clay Barrier and Geological Barriers. Montrael Canada, July 5-7.

Beles AA, Stanculescu II (1958) Thermal treatment a means of improving the stability of earth masses. Geotechnique 8 (4): 158-165.

Boudali M, Leroueil S, Murthy B R S (1994)Viscous Behavior of Natural Soft Clays. In: Proceedings of $13^{\text {th }}$ International Conference on Soil Mechanics and Foundation Engineering, pp 411-416.

Cho WJ, Lee JO, Kang CH (2000) Influence of temperature elevation on the sealing performance of the potential buffer material for a high-level radioactive waste repository. Ann Nuc Energy 27: 1271-1284.

de La Fuente S, Cuadros J, Fiore S, Linares J (2000) Electron microscopy study of volcanic tuff alteration to illite-smectite under hydrothermal conditions. Clays and Clay Minerals 48(3): 339-350.

Delage P, Sultan N, Cui YJ (2000) On the thermal consolidation of Boom clay. Can Geotech J 37 (2): 343-354.

Drief A, Martinez- Ruiz F, Nieto F, Sanchez NV (2002) Transmission electron 
microscopy evidence for experimental illitization of smectite in K-enriched seawater solution at $50^{\circ} \mathrm{C}$ and basic $\mathrm{pH}$. Clays and Clay Minerals, 50(6): 746756.

Estabragh AR, Rafatjo H, Javadi AA (2014) Treatment of an expansive soil by mechanical and chemical techniques. Geosynth Int 21(3):1-10.

Evans JC (1991) Geotechnics of hazardous waste control. Chapter 20 in foundation engineering handbook, vol. 2 by Hsai-Yang Fanf, Van Nostrand Reinhold, New York.

Fookes PG(ed) (1997) Tropical residual soils. Geological Society Professional Handbook London: The Geological Society.

Fredlund DG Rahardjo HR (1993) Soil Mechanics for unsaturated soils. John Wiley and Sons Ins. New York

Gens A (1996) Constitutive modelling: Application to compacted soils. In: Proceding of the $1^{\text {st }}$ International Conference on Unsaturated Soils. Vol.3, Baikema, Rotterdom, Netherlands, pp.1179-1200.

Graham J, Tanaka N, Crilly T, Alfaro M (2001) Modified Cam-Clay Modelling of Temperature Effects in Clays. Can Geotech J 38: 608-621.

Grim RE, Bradley WF (1948) Rehydration and dehydration of the clay minerals. Am Mineral 33: 50-59.

Gupta GC, Dutta AK (1967) Water stability of aggregates in a heated black cotton soil. Soil Sci 104 (3):210-216.

Hammel JE, Sumner ME, Burema J (1983) Atterberg limits as indices of external surface area of soils. Soil Sci Soc Am J 47:1054-1956.

Houston SL, Houston W N, Williams N D (1985) Thermo-Mechanical Behavior of Seafloor Sediments. J Geotech Eng 111(11): 1249-1263. 
Hueckel T, Baldi G (1990) Thermoplasticity of saturated clays: Experimental constitutive study. J Geotech Eng ASCE 116 (12):1778-1795.

Komine H (2013) Thermal influence on swelling pressure and swelling deformation of bentonites and investigation of its factors. In: Proceeding of the $18^{\text {th }}$ International Conference on Soil Mechanics and Geotechnical Engineering, paper No.2010, Paris, France.

Komine H, Ogata N (1996) Experimental study on swelling characteristics of compacted bentonite. Can Geotech J 31(4): 478-490.

Komine H. Ogata N (2003) New equations for swelling characteristics of bentonitebased buffer materials. Can Geotech J 40: 460-475.

Lambe TW (1962) Soil stabilization, Chap. 4 of Foundation Engineering, G.A. Leonards, Ed., McGraw Hill, New York

Laguros JG (1969) Effect of temperature on some engineering properties of clay soils. Effect of temperature and heat on engineering behaviour of soils. Special report 103, Highway Res. Board, Washington D.C., pp.9-27.

London F (1937) The general theory of molecular forces. Transaction of the Faraday Society 33: 8-26.

Mesri G, Olson RE (1971) Consolidation characteristics of montmorillonite. Géotechnique 21(4):341-352.

Mitchell JK (1993) Fundamentals of soil behaviour. Secound Edition, Published by John Wiley and Sons, Inc

Olson RE, Mesri G (1970) Mechanisms controlling the compressibility of clay. J Soil Mech and Found Dive ASCE 96(SM6):1863-1878. 
Plum RL, Esrig MI (1969) Some temperature effects on soil compressibility and pore pressure. Effects of temperature and heat on engineering behaviour of soils. Special report 103, Highway Res. Board, Washington D.C., pp.231-242.

Pusch R, Karlnland O, Hokmark H (1990) GMM-a general microstructural model for qualitative and quantitative studies of smectite clays. SKB Technical Report 90-43, Stockholm, Sweden.

Rao SM, Thyagaraj T (2007) Swell-compression behaviour of compacted clays under chemical gradient. Can Geotech J 44:520-532.

Romero E, Villar MV, Lloret A (2005) Thermo-hydromechanical behaviour of heavily overconsolidated clays. Eng Geol 81: 255-268.

Romero E, Gens A, Lloret A (2003) Suction effects on a compacted clay under nonisothermal conditions. Geotechnique 53(3):65-81.

Schreiner HD (1987) Stress paths during swelling of soils compacted dry of the plastic limit. Proceeding of the $6^{\text {th }}$ International Conference on Expansive Soil. New Delhi, Vol.1, pp.395-398.

Sridharan A, Rao GV (1973 Mechanism controlling volume change of saturated clays and role of effective stress concept. Géotechnique 23:359-371.

Sridharan A, Rao AS, Sivapullaiah PV (1986) Swelling pressure of clays. Geotech Test J 9: 24-33.

Sridharan A, Choudhury D (2002) Swelling pressure of sodium montmorillonites. Géotechnique, 52(6): 459-462.

Tang AM, Cui YJ, Barnel N (2008) Thermo-mechanical behaviour of compacted swelling clay. Geotechnique 58 (1):45-54. 
Towhata I, Kuntiwatanakul P, Kobayashi H (1993) Volume change of clays induced by heating as observed in consolidation test. Soils Found 33 (4):170183.

Villar MV, Lloret A (2004) Influence of temperature on the hydro-mechanical behaviour of a compacted bentonite. Appl Clay Sci 26 (1-4):337-350.

Volckaert G, Manfroy P (1992) Characteristics of Argillaceous Rocks- A Catalogue of the Characteristics of Argillaceous Rocks under investigation in the radioactive Waste Programms of belgiuh, Canada, France, Italy, Japan, Spain, Switzerland and United Kingdom.

Volckaert G, Bernier F, Alonso E, Gens A, Samper J, Villar M, Martin-Martin PL, Cuevas J, Campos R, Thomas H, Imbert C, Zingarelli V (1993) Model development and validation of the thermal-hydraulic-mechanical and geomechanical behaviour of the clay barrier. Annual progress report on CEC Contract No. F12W-CT90-0033 and F12W-CT91-0102.

Wang MC, Benway JM, Arayssi AM (1990) The Effect of Heating on Engineering Properties of Clays, Physico-Chemical Aspects of Soil and Related Materials, ASTM STP 1095, K. B. H. a. R. O. Lamb, ed., ASTM, pp. $139-158$.

Wersin P, Johnson LH, McKinley IG (2006) Performance of the bentonite barrier at temperatures beyond $100^{\circ} \mathrm{C}$ : A critical review. Physics and Chemistry of the Earth 32(8): 780-788.

Yan X, Luo M (1995) Physical chemistry. Wuhan University Press Wohan China.

Yong RN, Mohamed AMO, Warkentin BP (1992) Principals of contaminant transport in soils. Developments in Geotechnical Engineering, 73, Publisher by Elesevir 
Youssef M S, SabryA, Ramli AHE (1961) Temperature Changes and

Their Effects on Some Physical Properties of Soils, Proceedings of 5th

International Conference on Soil Mechanics and Foundations, pp. 419-421.

Zhang G, Germaine JT, Whittle AJ, Ladd CC (2004) Index properties of a highly weathered old alluvium. Géotechnique 54(7): 441- 


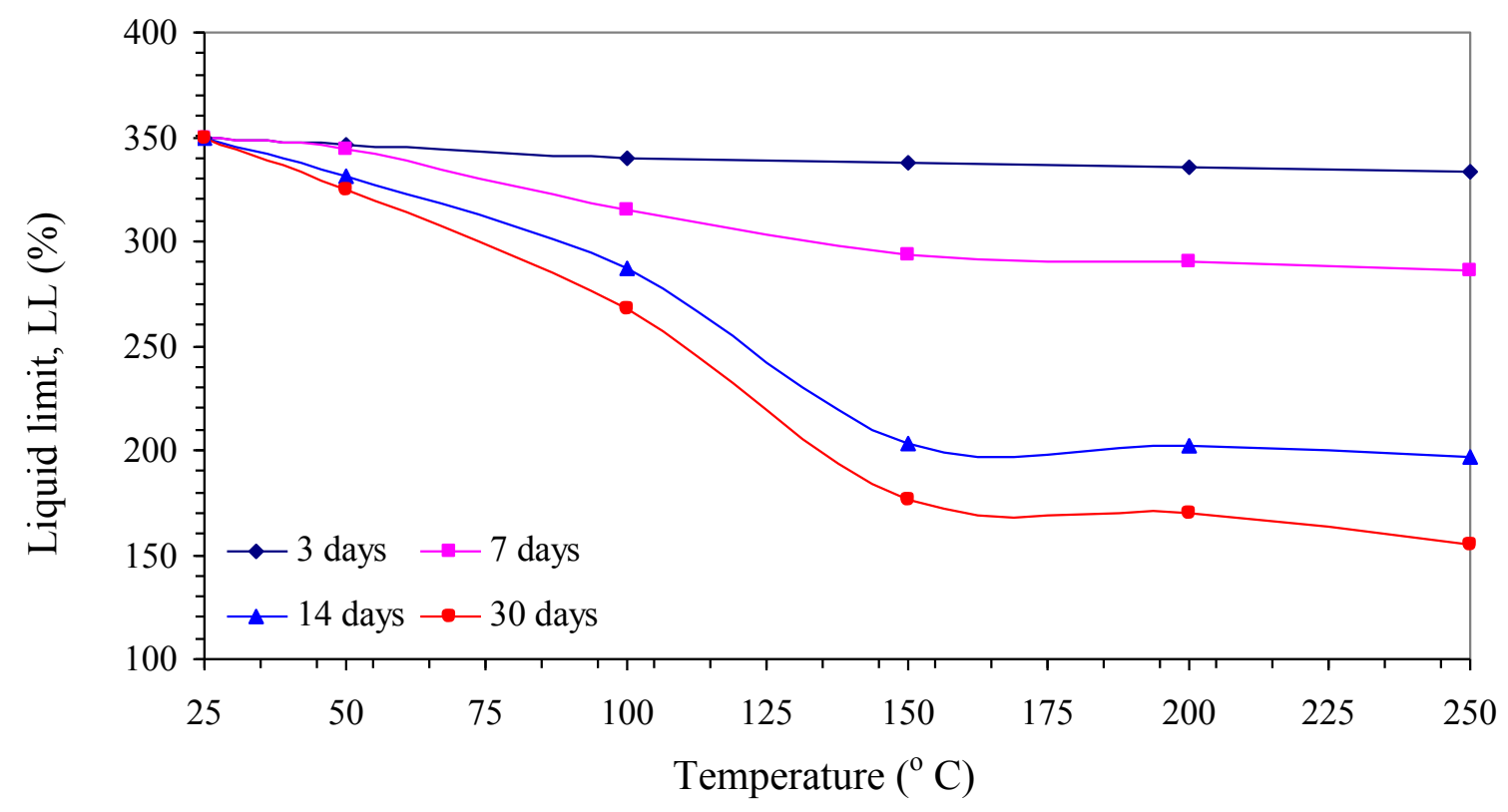

(a)

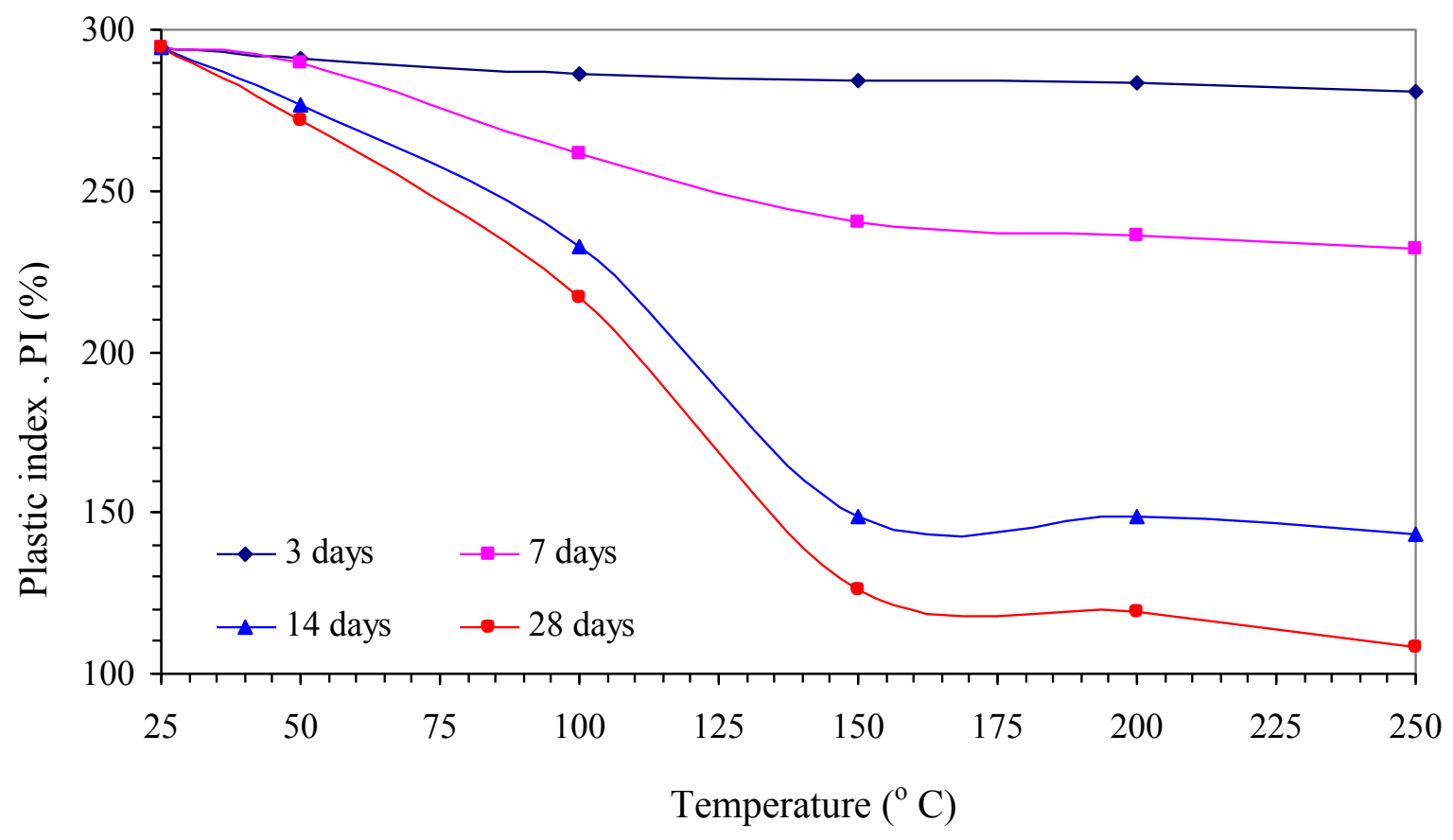

(b)

Fig.1. (a): variations of liquid limit (LL) with temperature, (b): variations of plastic index (PI) with time 


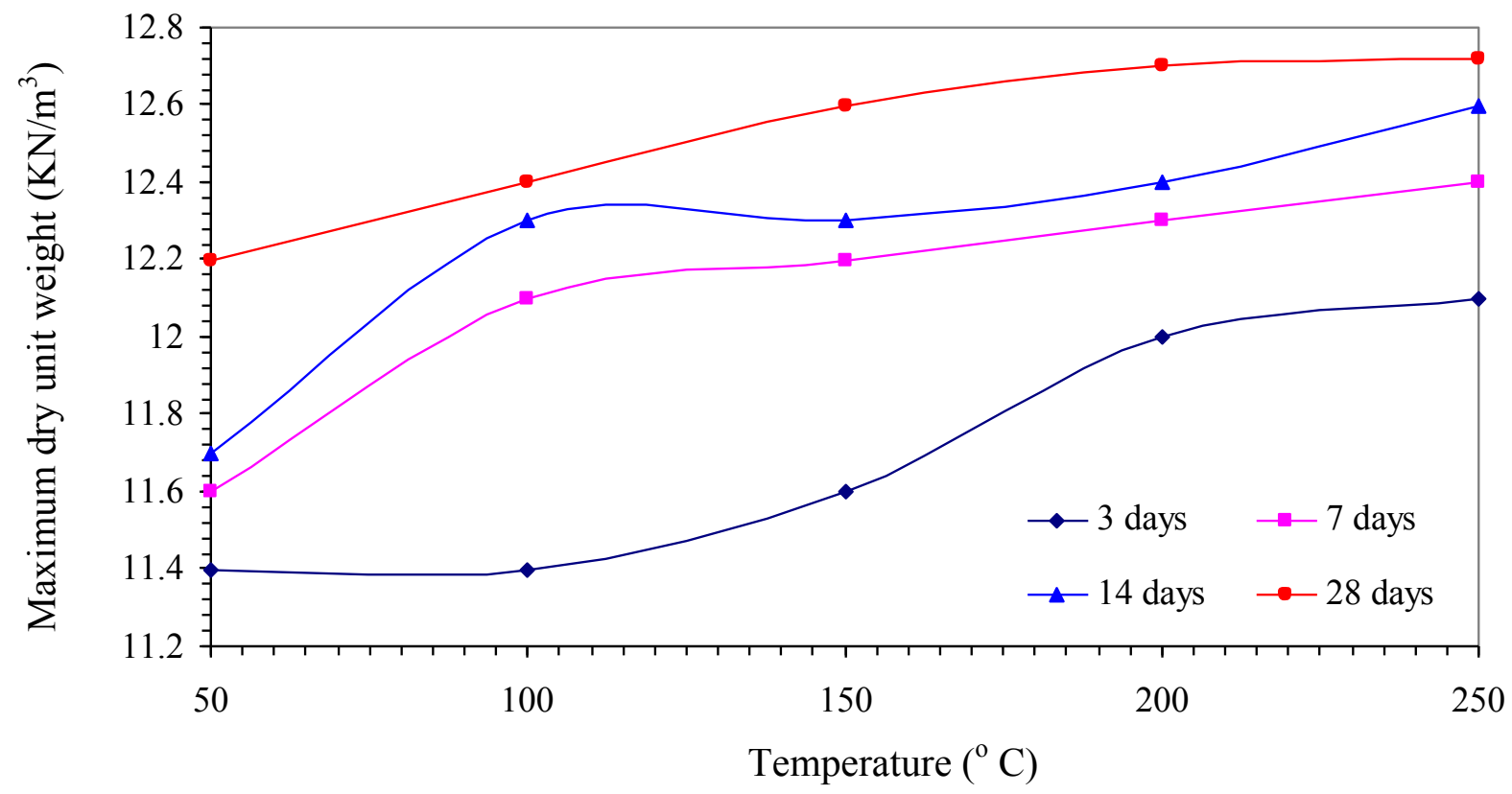

(a)

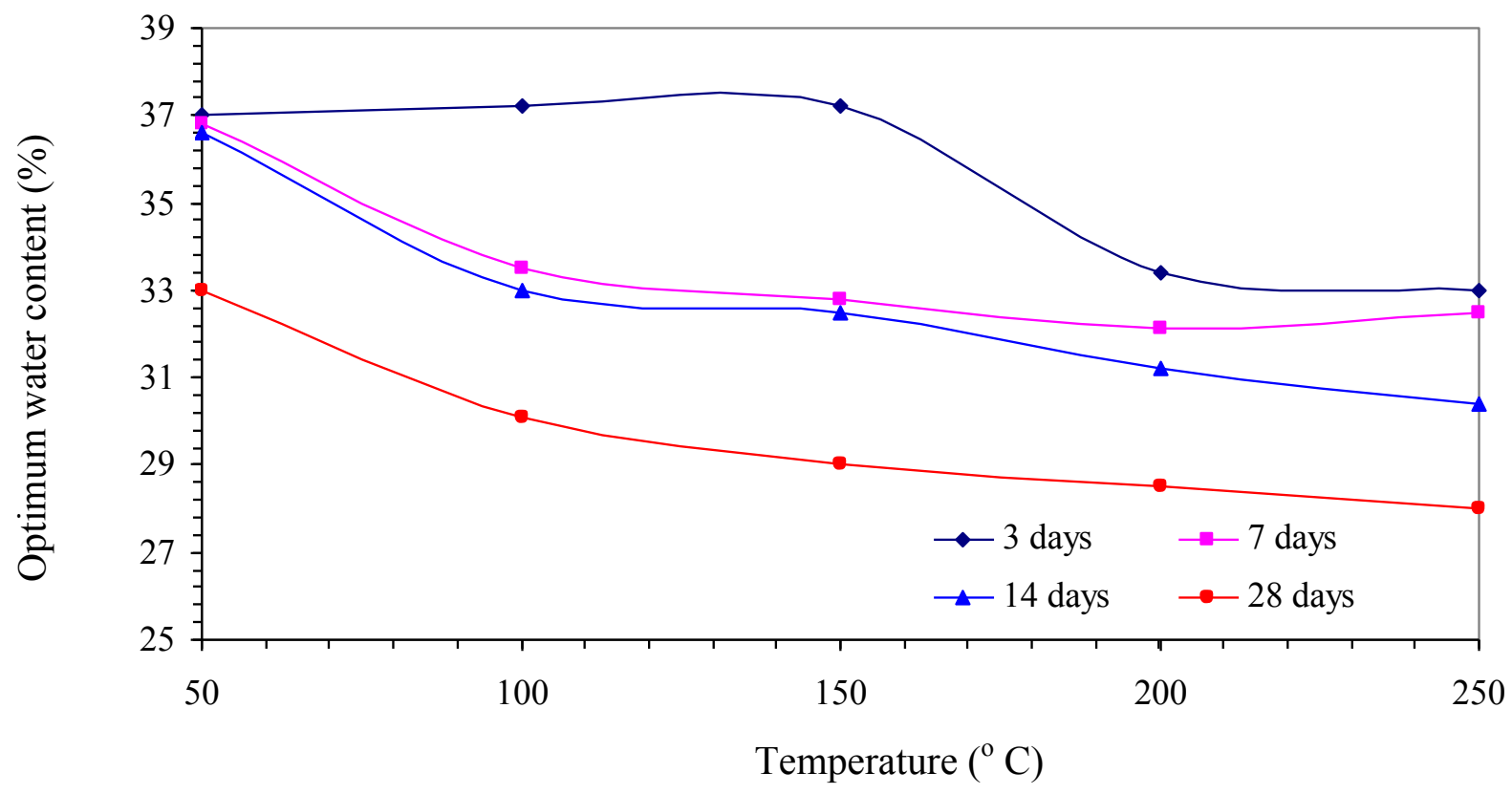

(b)

Fig. 2 . (a): variations of maximum dry unit weight with temperature. (b) variations of optimum water content with temperature 


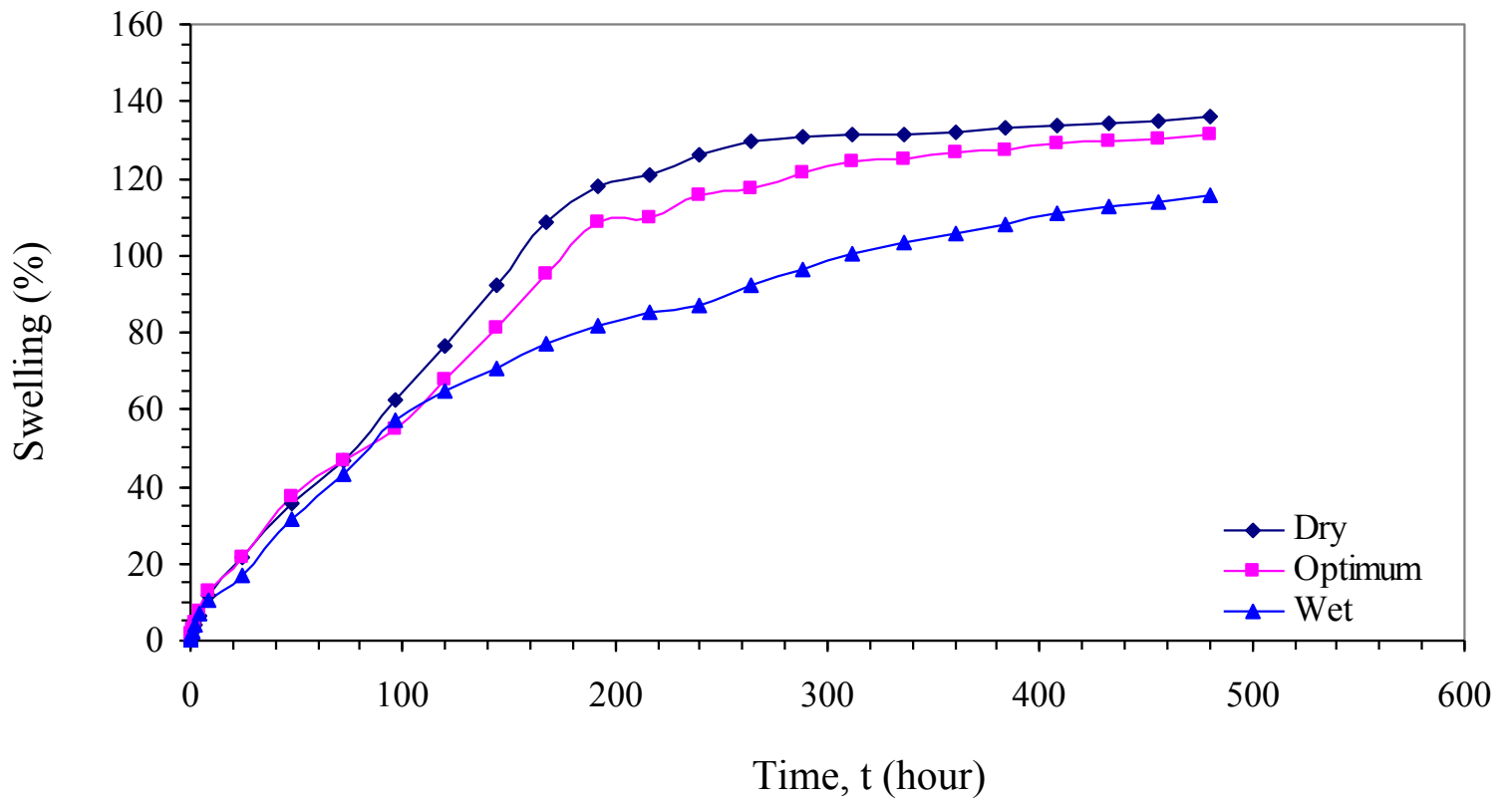

(a)

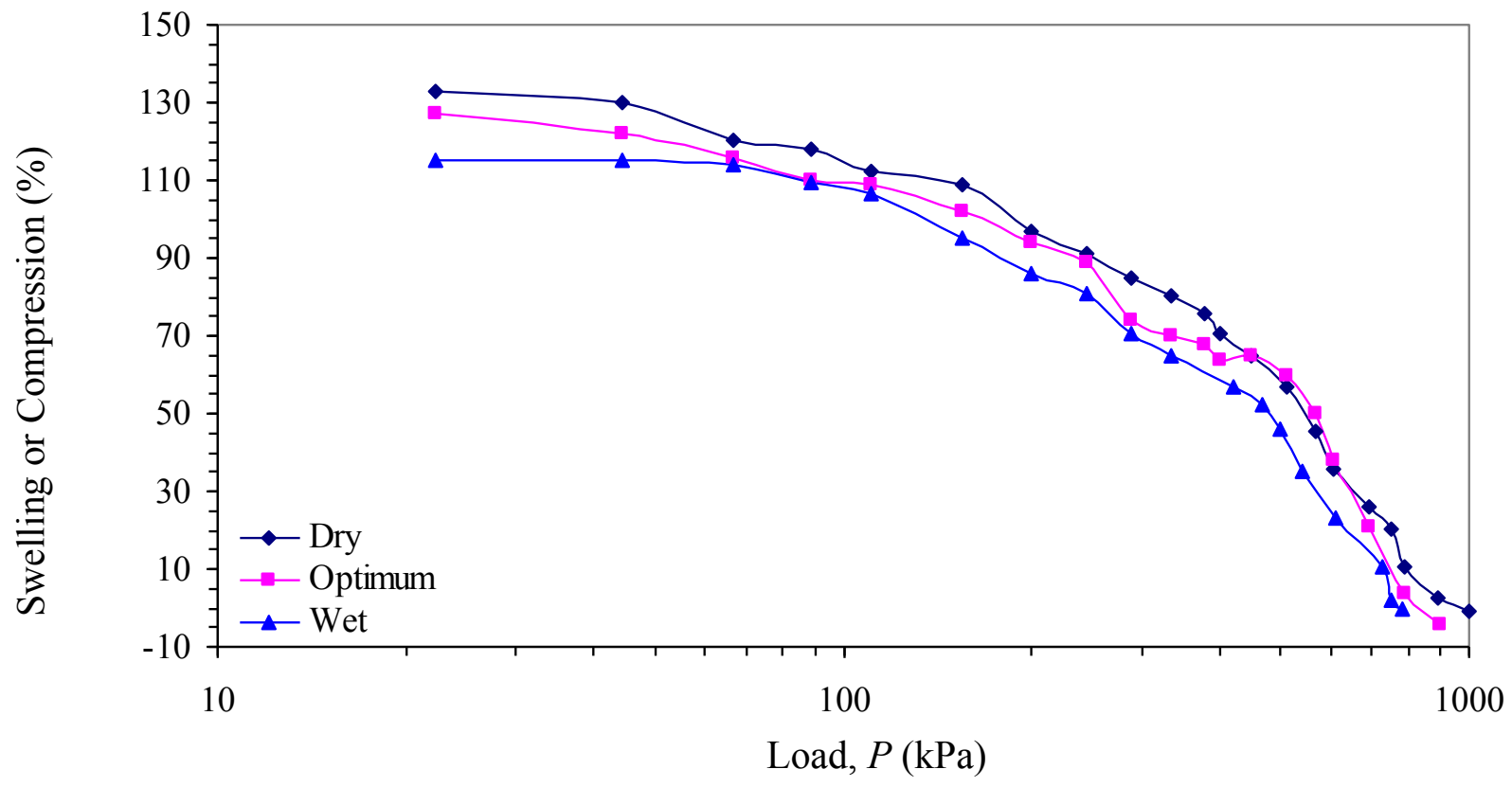

(b)

Fig.3. (a): variations of swelling (\%) with time (b): variations of compression or swelling with load for dry, optimum and wet of natural soil samples 


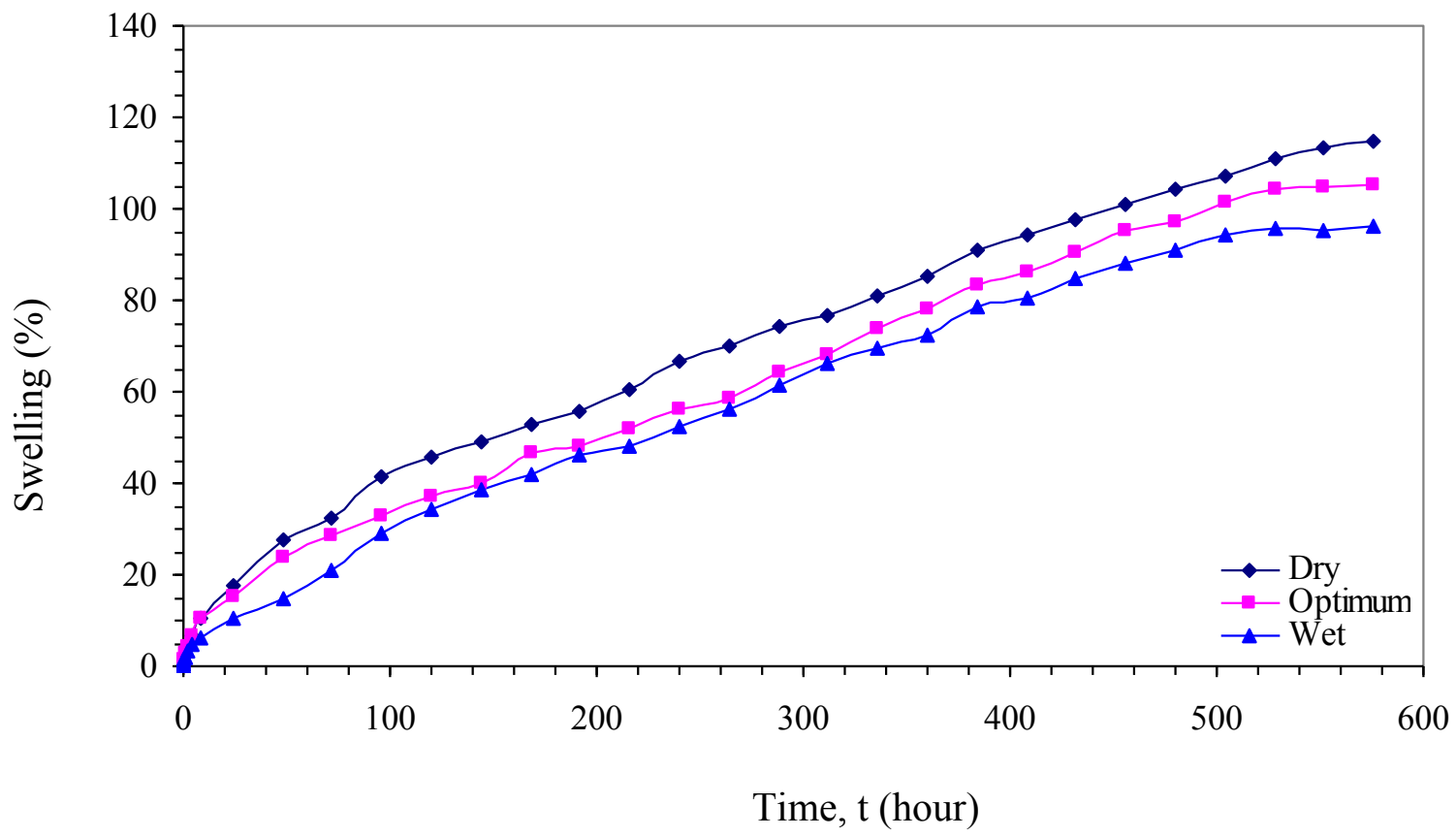

(a)

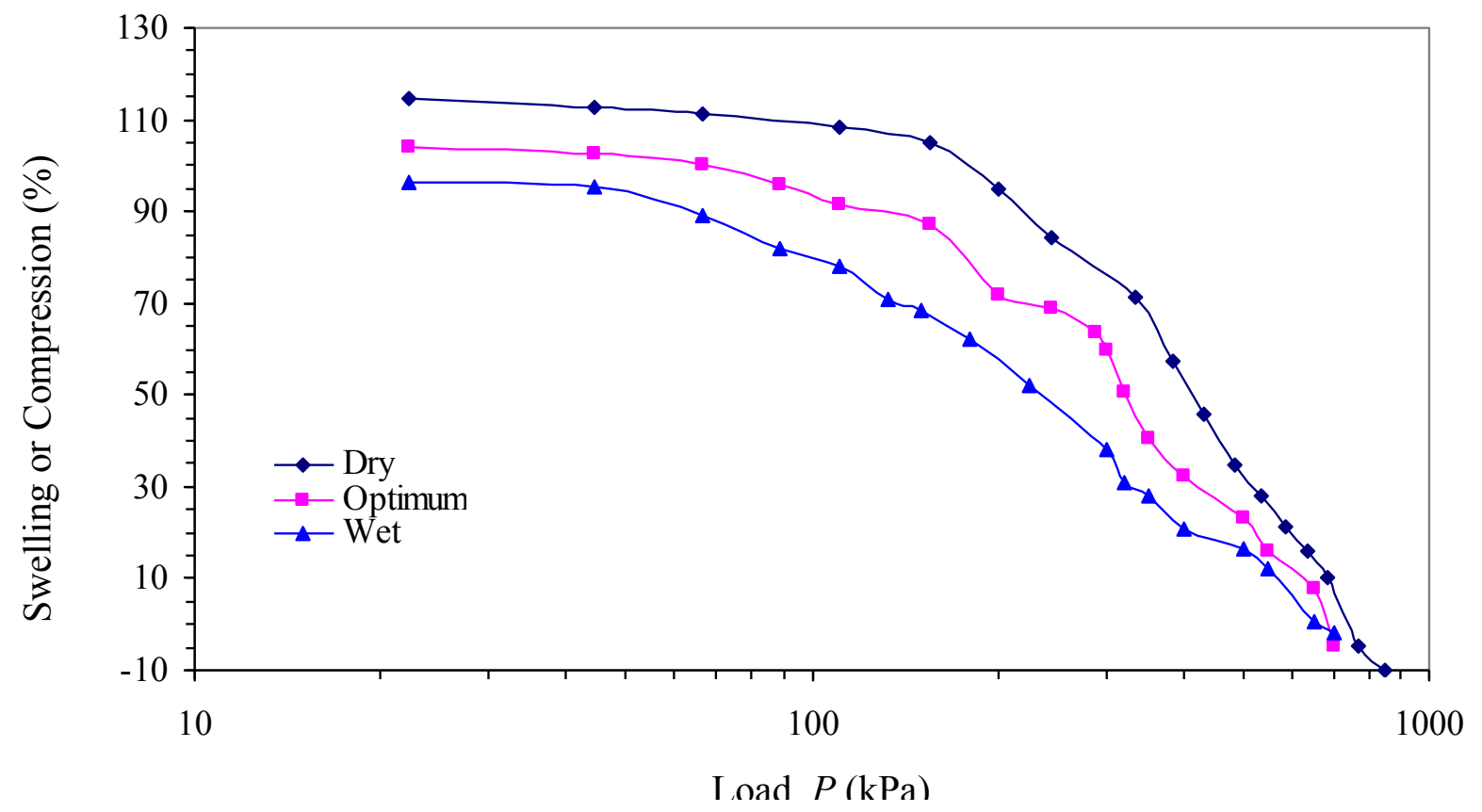

(b)

Fig.4. (a): variations of swelling (\%) with time (b): variations of compression or swelling with load for dry, optimum and wet of soil samples at $\mathrm{T}=100^{\circ} \mathrm{C}$ for $\mathrm{t}=3$ days 


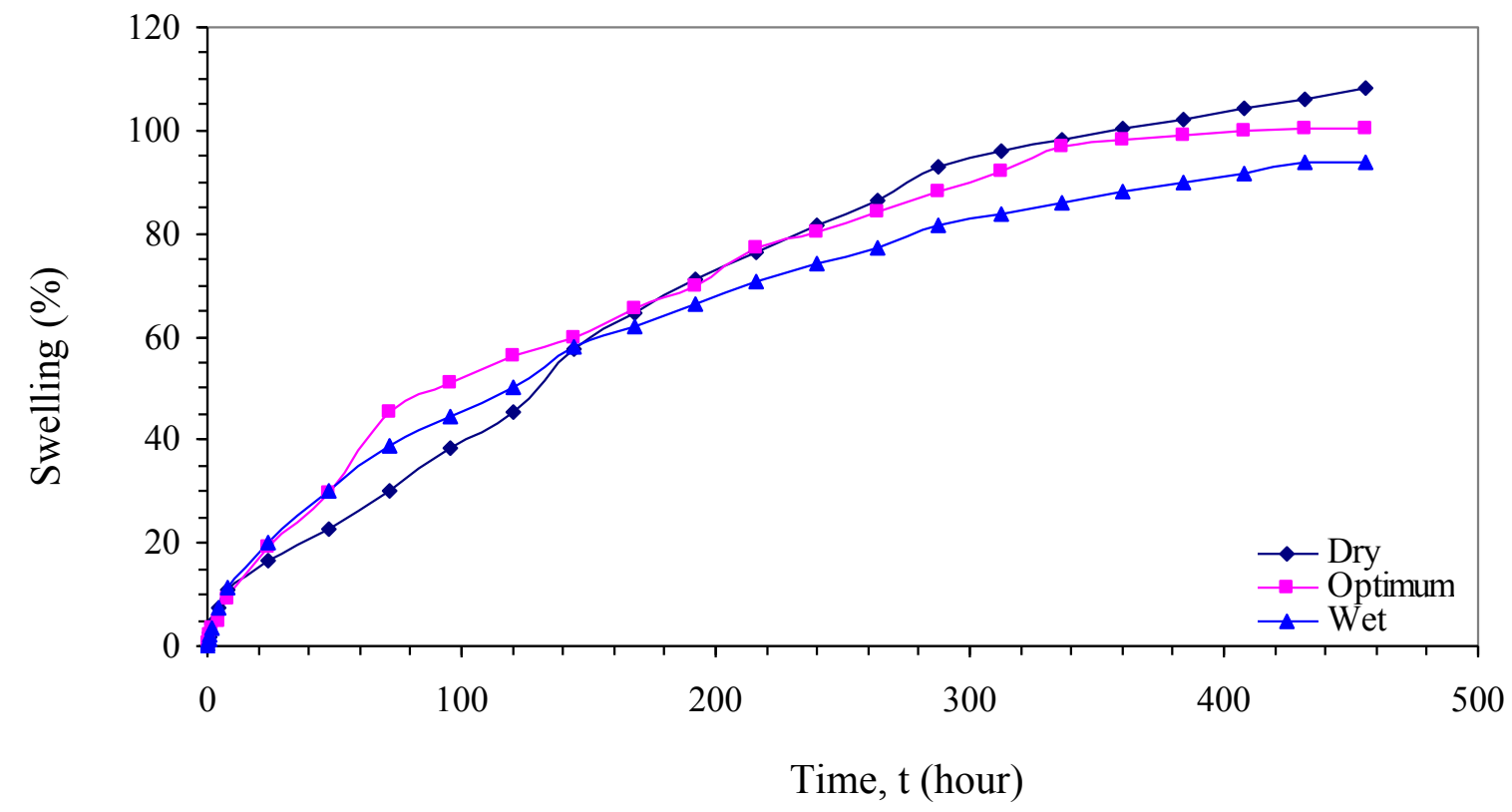

(a)

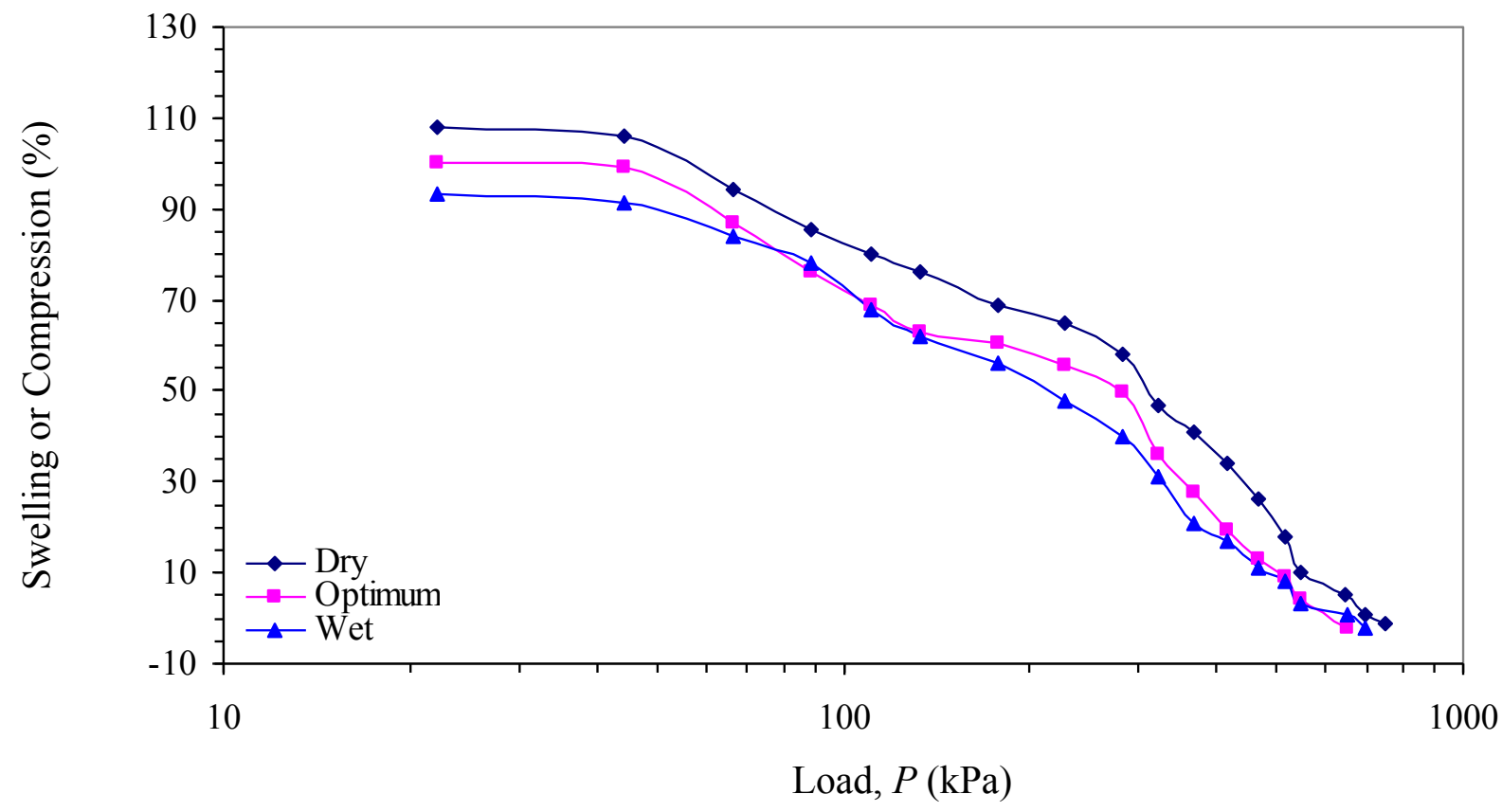

(b)

Fig.5. (a): variations of swelling (\%) with time (b): variations of compression or swelling with load for dry, optimum and wet of soil samples at $\mathrm{T}=100^{\circ} \mathrm{C}$, for $\mathrm{t}=30$ days 


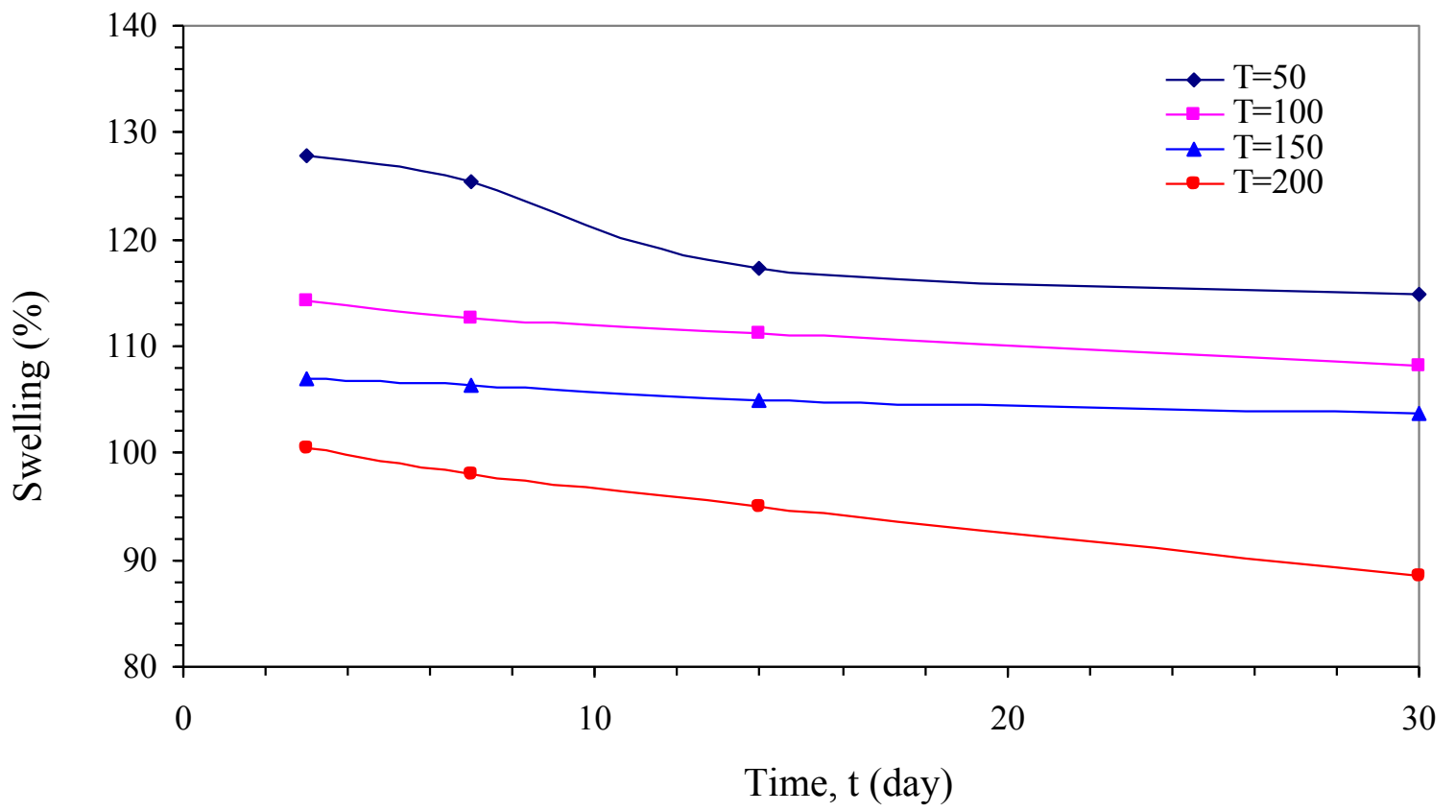

(a)

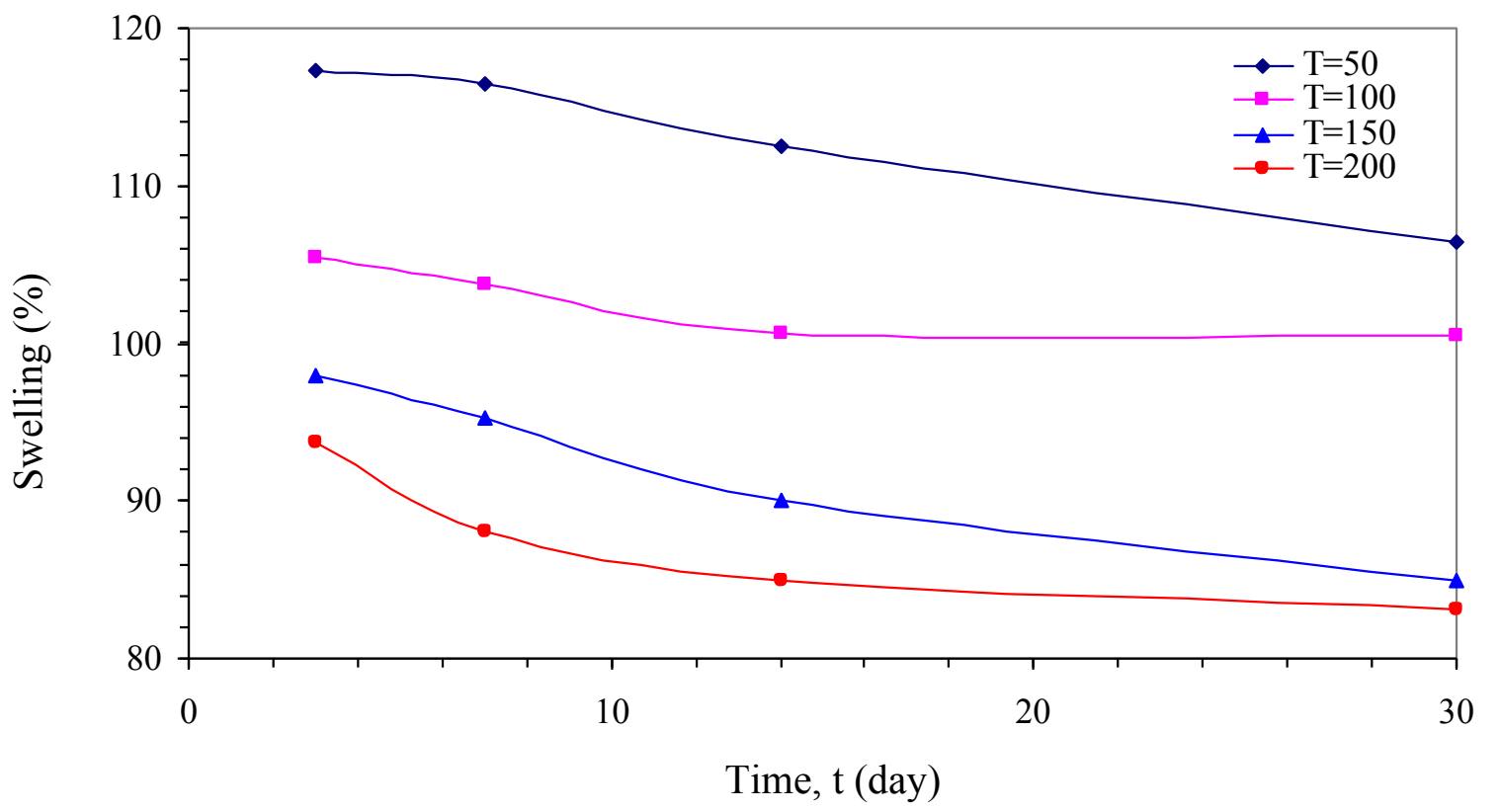

(b) 


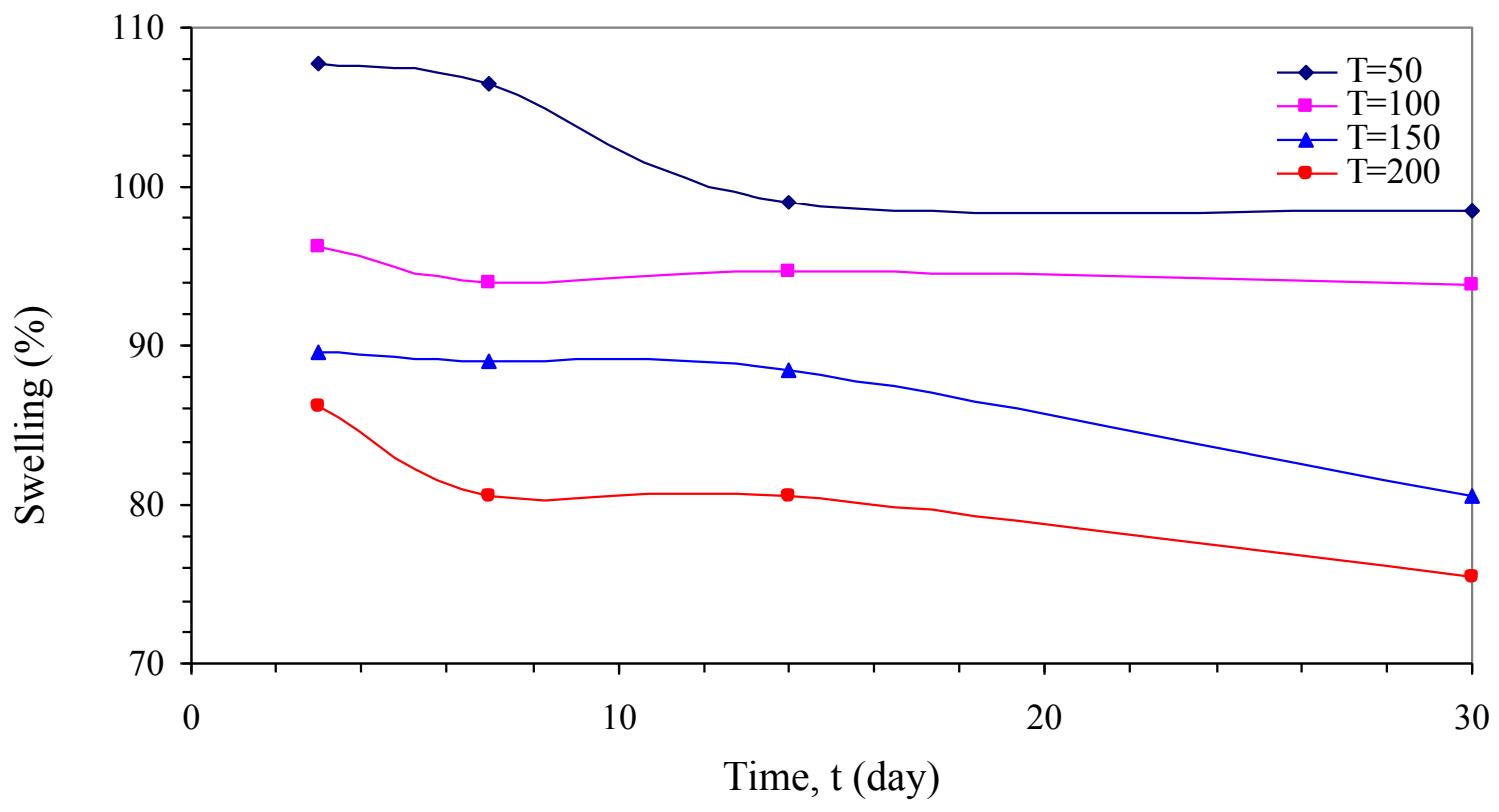

(c)

Fig.6. Variations of swelling against time for different temperature (a): dry side, (b); optimum, (c): wet side

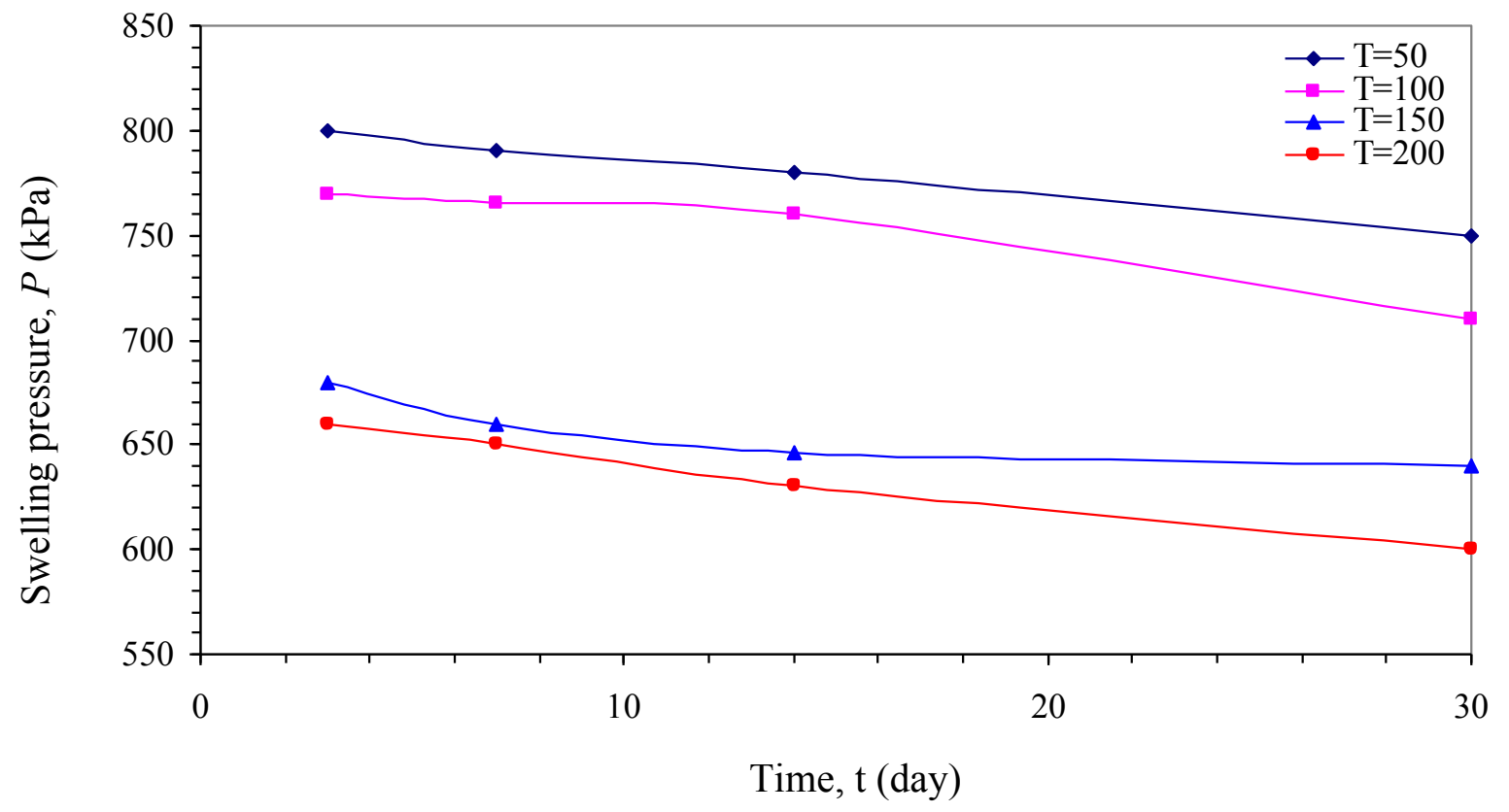

(a) 


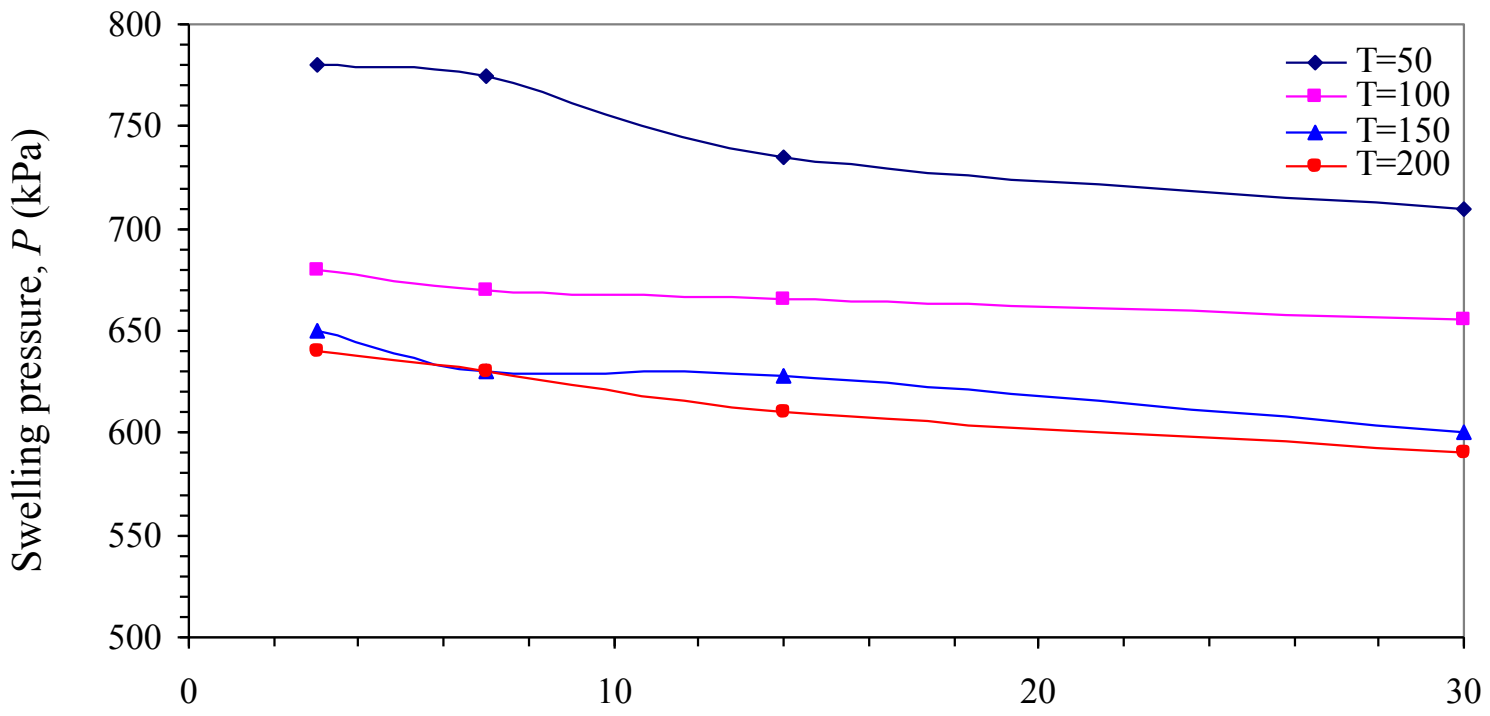

Time, $\mathrm{t}$ (day)

(b)

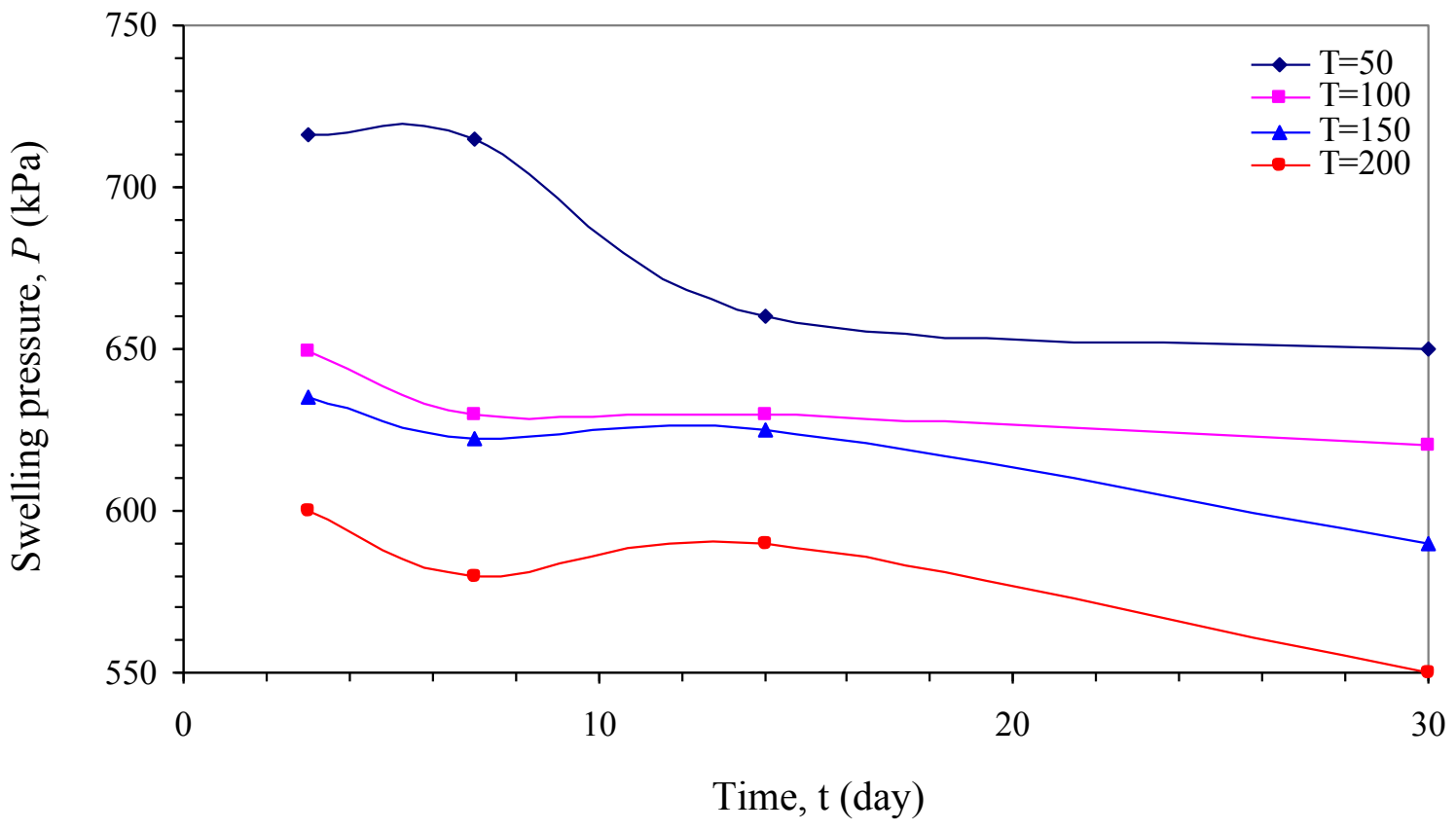

(c)

Fig.7. Variations of swelling pressure against time for different temperature (a): dry side, (b); optimum, (c ): wet side 


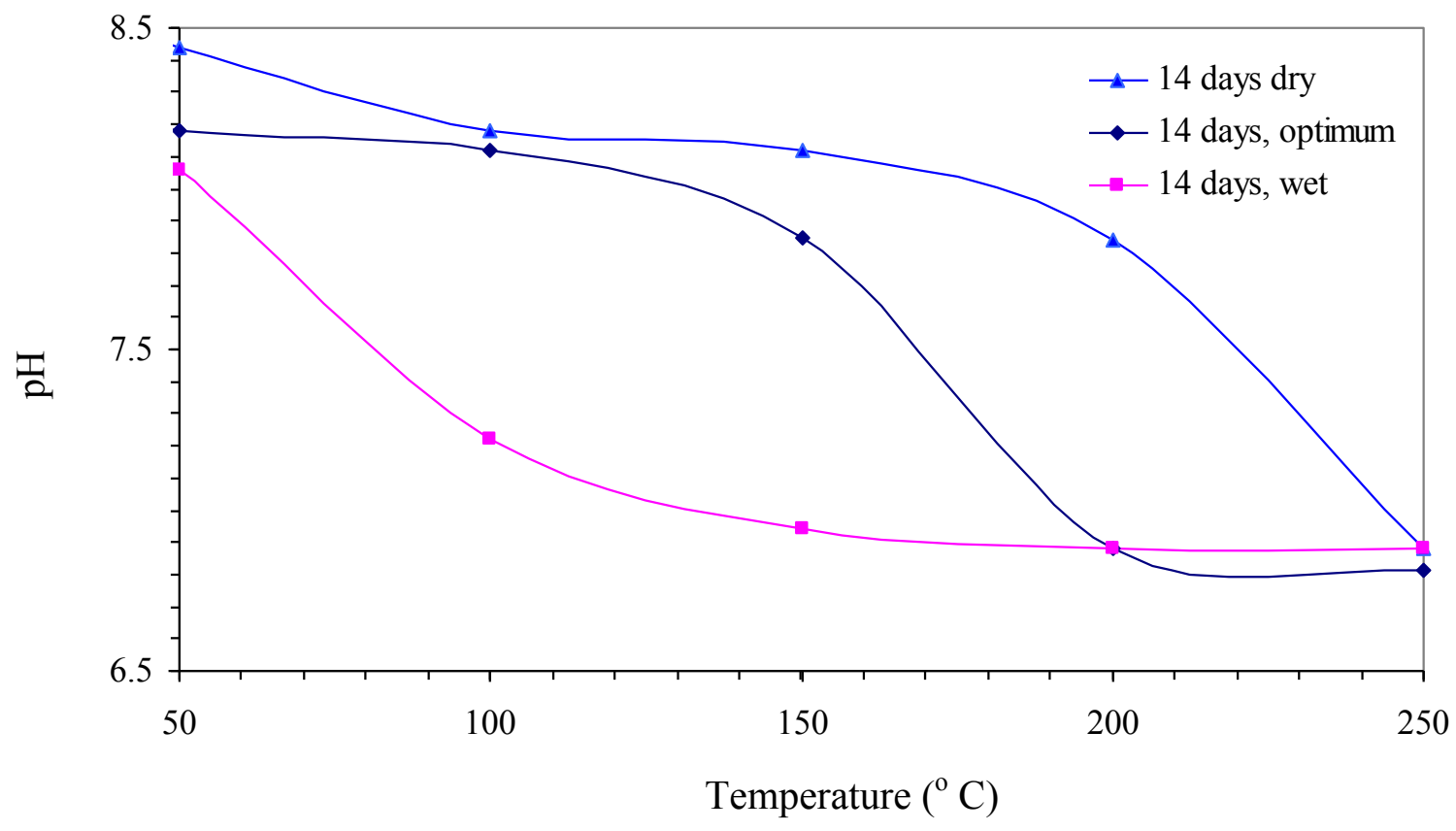

(a)

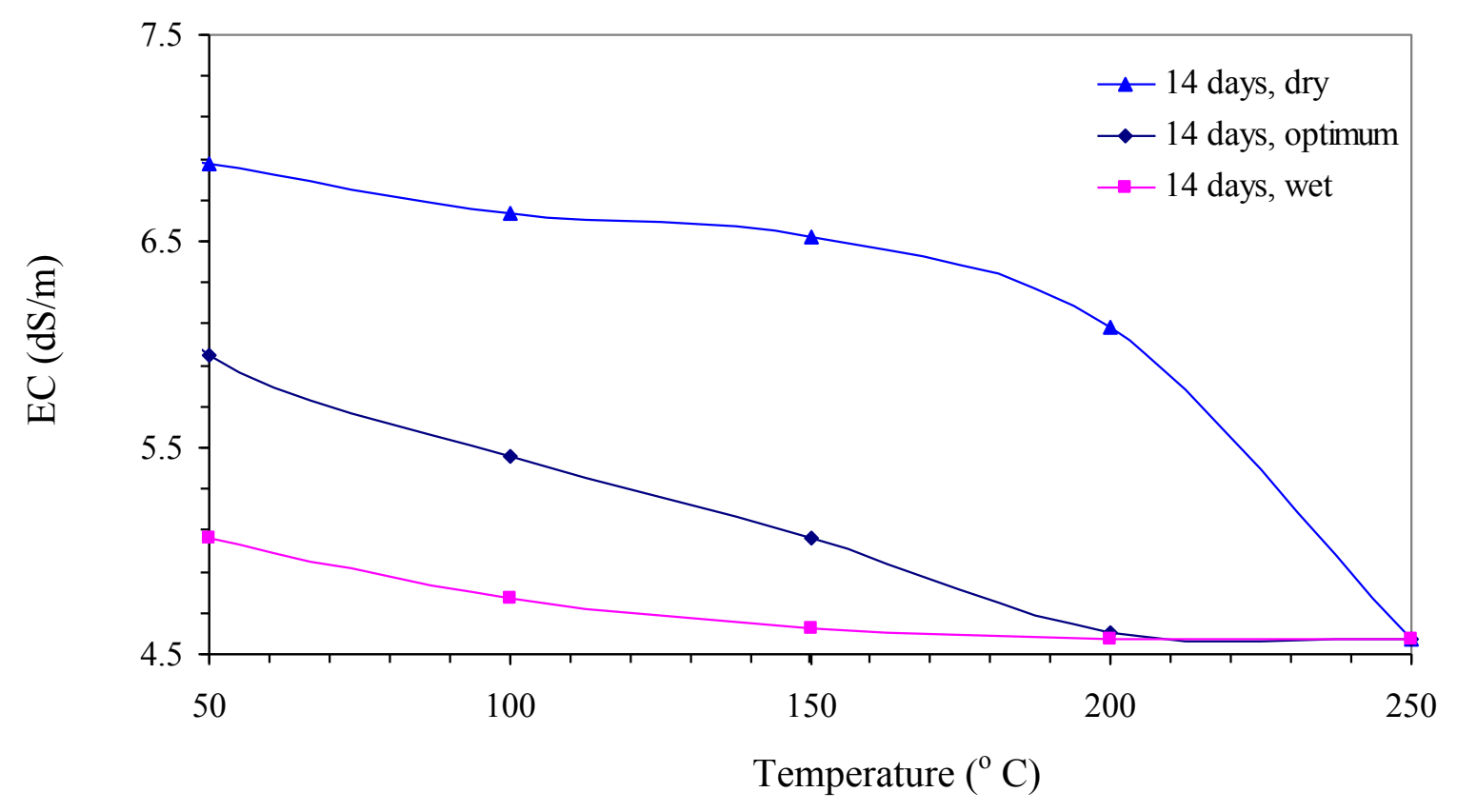

(b) 


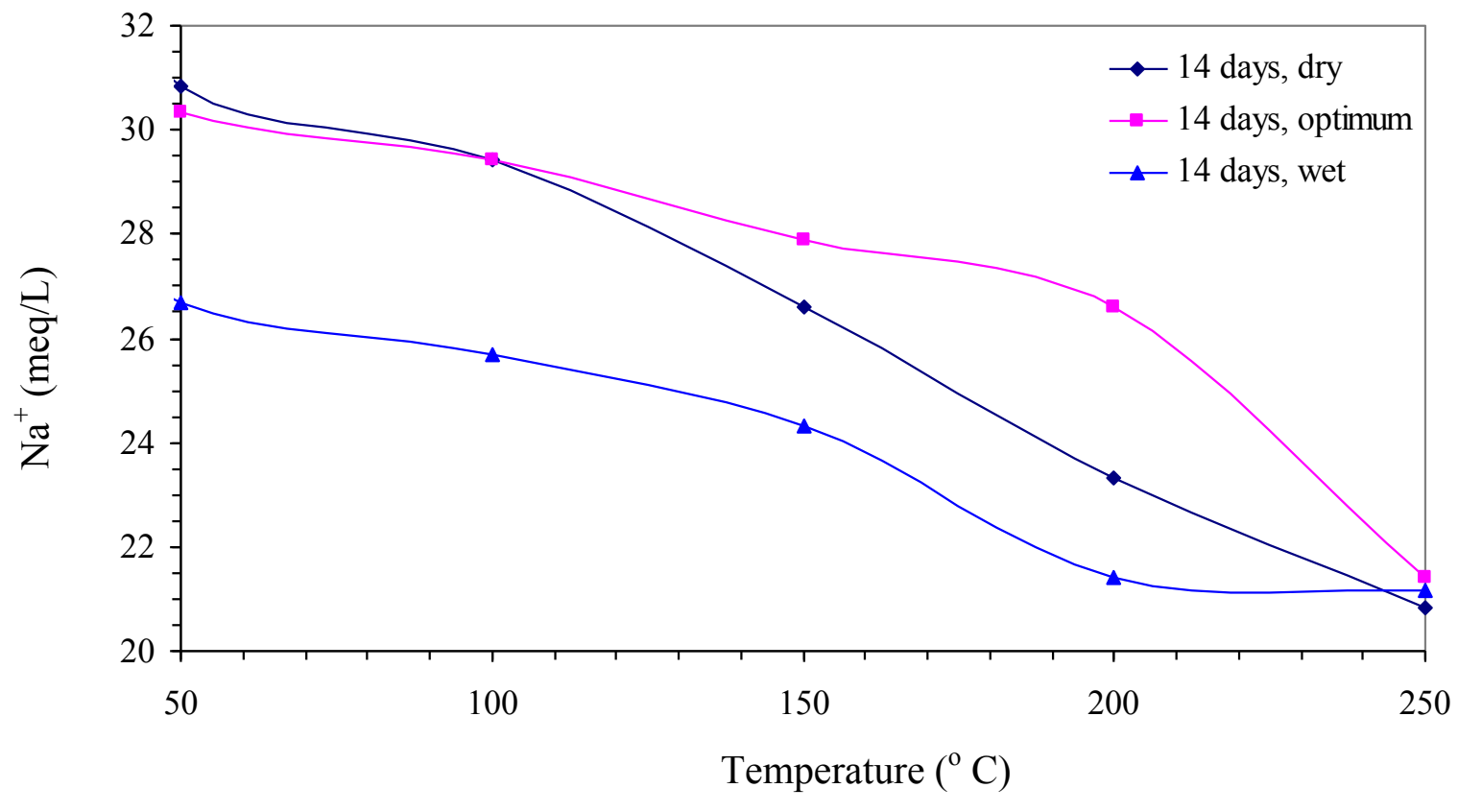

(c)

Fig.8. Variations of $\mathrm{pH}(\mathbf{a}), \mathrm{EC}$ (b) and $\mathrm{Na}^{+}$(c) against temperature for samples on dry, optimum and wet sides at time $=14$ days 